\title{
Systems Biology Perspectives on Cerebellar Long-Term Depression
}

\author{
Hideaki Ogasawaraa ${ }^{a}$, Tomokazu Doic ${ }^{c}$ Mitsuo Kawato ${ }^{b}$

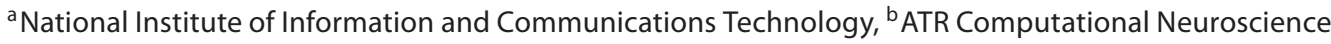 \\ Laboratories, Kyoto, and ' Osaka Bioscience Institute, Osaka, Japan
}

\section{Key Words}

Cerebellum • Long-term depression • Systems biology •

Simulation $\cdot$ Intracellular signaling cascade $\cdot$

Protein kinase $M \zeta$

\begin{abstract}
Long-term depression (LTD) at parallel fiber-Purkinje cell (PF-PC) synapses is thought to be the cellular correlate of cerebellar associative learning. The molecular processes are, in brief, phosphorylation of AMPA-type glutamate receptors (AMPARs) and their subsequent removal from the surface of the PF-PC synapse. In order to elucidate the fundamental mechanisms for cerebellar LTD and further the understanding of its computational role, we have investigated its systems biology and proposed the following hypotheses, some of which have already been experimentally verified: (1) due to the mitogen-activated protein kinase (MAPK)-protein kinase $C$ (PKC) positive feedback loop, phosphorylation of AMPARs is an all-or-none event; (2) the inositol 1,4,5-triphosphate receptor detects concurrent PF and climbing fiber inputs, forming the cellular basis for associative learning, and (3) the local concentration of nitric oxide in the PC dendrite reflects the relevance of a given context, enabling context-dependent selection of learning modules within the cerebellum. In this review, we first introduce theoretical studies on cerebellar LTD, mainly focusing on our own published work, followed by a discussion of the effects of stochasticity, localization, diffusion, and scaffolding. Neu-
\end{abstract}

rons embody two features that are apparently contradictory, yet necessary for synaptic memory: stability and plasticity. We will also present models for explaining how neurons solve this dilemma. In the final section, we propose a conceptual model in which a cascade of excitable dynamics with different time scales, i.e., $\mathrm{Ca}^{2+}$-induced $\mathrm{Ca}^{2+}$ release, the MAPK-PKC positive feedback loop, and protein kinase $M \zeta$

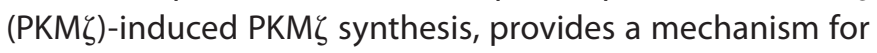
stable memory that is still amenable to modifications.

Copyright $\odot 2008$ S. Karger AG, Basel

\section{Introduction}

The cerebellum is important in motor coordination, adaptation, and learning, as well as in language, cognition, and many other aspects of life [reviewed in 1-7]. It is thought to be a specialized organ for supervised learning (also known as associative learning, through which each input signal is specifically associated with a desired output) $[8,9]$. The main neurons and wirings in the cerebellar cortex include Purkinje cells (PCs), parallel fibers (PFs), and climbing fibers (CFs). PCs provide the sole output from the cortex, and each $\mathrm{PC}$ receives two types of excitatory inputs: one from hundreds of thousands of PFs and the other from a single CF. The Marr-Albus-Ito theory [10-12] states that their neuronal circuit underlies associative learning. In the theory, PFs provide a sensorimotor context to PCs, while CFs carry teacher signals

\section{KARGER \\ Fax +4161306 1234 E-Mail karger@karger.ch} www.karger.com
(C) 2008 S. Karger AG, Basel

$1424-862 X / 08 / 0164-0300 \$ 24.50 / 0$

Accessible online at:

www.karger.com/nsg
Dr. Hideaki Ogasawara

ATR Computational Neuroscience Laboratories

2-2-2, Hikaridai, Seikacho, Kyoto 619-0288 (Japan)

Tel. +81 77495 2688, Fax +81 774951259

E-Mail ogahide@atr.jp 
that modify PF-PC synapses in an associative manner. After a long investigation, the PF-PC synapse was experimentally demonstrated to be plastic; its transmission efficacy was depressed when the CF and PF were repetitively and synchronously activated (cerebellar long-term depression or LTD) [13]. Subsequent in vitro studies have revealed that LTD is regulated by $\left[\mathrm{Ca}^{2+}\right][14-16]$ and that $\left[\mathrm{Ca}^{2+}\right]$ elevation and PF-PC LTD are most prominent when PF stimuli precede CF stimuli by $50-250 \mathrm{~ms}$ [17, 18] (N.B.: In this article, [substance] stands for the concentration of the substance). In behaving animals, CF inputs are delayed $\sim 100 \mathrm{~ms}$ with respect to $\mathrm{PF}$ inputs $[3-5,11]$, due to the definite sequence of events during motor execution (more specifically, first, $\mathrm{PCs}$ receive $\mathrm{PF}$ inputs, motor commands are given and followed by a motion, the feedback control circuit generates feedback motor commands, which are finally transmitted through $\mathrm{CFs}$ to the PCs as error signals [3]). The similarity between the in vitro time window size and in vivo PF-CF delay length strongly supports the Marr-Albus-Ito theory that PF-PC plasticity is the cellular process of cerebellar learning [10-12], although some controversies exist $[19,20]$.

The molecular mechanism of PF-PC LTD involves the internalization of $\alpha$-amino-3-hydroxy-5-methylisoxazole-4-propionic acid (AMPA)-type glutamate receptors (AMPARs), which occurs when activated protein kinase $\mathrm{C}$ (PKC) phosphorylates the receptor GluR2 subunit. Essential molecules for LTD include mitogen-activated protein kinase (MAPK), MAPK kinase (MAPKK), MAPKK kinase (MAPKKK), PKC, phospholipases A2 (PLA2) and C (PLC), arachidonic acid (AA), inositol 1,4,5-triphosphate $\left(\mathrm{IP}_{3}\right)$, and many others [reviewed in 4, 7, 21-26].

Postsynaptic long-term potentiation (LTP) reverses PF-PC LTD [27-29]. Without such reversal mechanisms, LTD would eventually reach saturation, preventing the occurrence of further learning events. A presynaptically synthesized messenger nitric oxide (NO) is a crucial 'gatekeeper' [30] for cerebellar plasticity; LTD and LTP are induced only in the presence of $\mathrm{NO}$, and its deprivation prevents both LTD and LTP [27, 31-36, reviewed in $7,37]$. The direction of gain change is $\left[\mathrm{Ca}^{2+}\right]$-dependent, with a high threshold for LTD and a low threshold for LTP $[25,29]$. Cerebellar adaptation has also been shown to be NO-dependent [38-40].

The number of molecular species known to engage in PF-PC plasticity is still increasing; $\mathrm{Ca}^{2+} /$ calmodulindependent protein kinases II (CaMKII) [41] and IV (CaMKIV) [42, 43], 82 receptors [44, 45], and endocannabinoid [46] are among the growing list. However, an extension of this list of implicated molecules does not necessarily further the fundamental understanding of plasticity mechanisms. As has been claimed [47], it is important to determine the minimal set of 'mediators' and their interactions that are essential in the memory formation processes.

To elucidate the key pathways of LTD and their computational roles in cerebellar learning, we have studied the systems biology of PF-PC synaptic plasticity and proposed the following hypotheses: (1) MAPK and PKC activate each other, generating a positive feedback loop, and because of this loop, phosphorylation of AMPARs is an all-or-none event [48]; (2) the $\mathrm{IP}_{3}$ receptor $\left(\mathrm{IP}_{3} \mathrm{R}\right)$ is capable of detecting conjunctive PF and CF inputs [49], which is a necessary feature for cerebellar associative learning; (3) NO reflects the relevance of a given context and enables context-dependent selection of learning modules in the cerebellum [30]. In this article, we first review the theoretical studies on cerebellar LTD, mainly focusing on our own published work, followed by a discussion of the possible effects of stochasticity, localization, diffusion, and scaffolding on synaptic transmission and plasticity. The brain is capable of learning new things while maintaining old memory. At the cellular level, this means that synapses must be both stable and plastic at the same time. How do they attain these contradictory characteristics [50]? We will present models for explaining how neurons solve the 'stability versus plasticity dilemma'. In the final section, we propose a conceptual model in which cerebellar LTD is induced and maintained by successive activation of three bistable dynamics with different time scales - $\mathrm{Ca}^{2+}$-induced $\mathrm{Ca}^{2+}$ release, the MAPK-PKC positive feedback loop, and protein kinase $\mathrm{M} \zeta$ (PKM $\zeta$ )-induced PKM $\zeta$ synthesis. This molecular network is predicted to make cerebellar memory stable for a very long period of time but still amenable to modifications.

\section{Simulation Studies on Cerebellar LTD}

\section{The MAPK-PKC Positive Feedback Loop Is the Cerebellar LTD Switch}

The mechanisms by which cells respond to transient and/or graded stimuli, and exhibit a switch-like behavior, have been drawing researchers' interest for decades [reviewed in 51-56]. One such mechanism produces a continuous response that is more sensitive than MichaelisMenten kinetics to changes in the stimulus amplitude; it 
Fig. 1. Signaling cascades of cerebellar LTD. a The MAPK cascade. MAPKK-P and MAPKK-PP denote singly and doubly phosphorylated MAPKK, respectively. MAPK-P and MAPK-PP denote singly and doubly phosphorylated MAPK. P'ase denotes phosphatase. Adapted from Huang and Ferrell [67]. Copyright 1996 by the National Academy of Sciences. b Schematic view of signaling cascades in cerebellar LTD. Reactions surrounded in the bold gray line take place inside the dendritic spine. $\mathbf{i}$ Dark gray area $=$ the MAPK-PKC positive feedback loop [48] and its peripherals. ii Light gray area $=$ PF-CF coincidence detection mechanisms [49]. Glu = Glutamate; $\mathrm{PKG}=$ cGMP-dependent protein kinase; PIP2 = phosphatidylinositol bisphosphate.

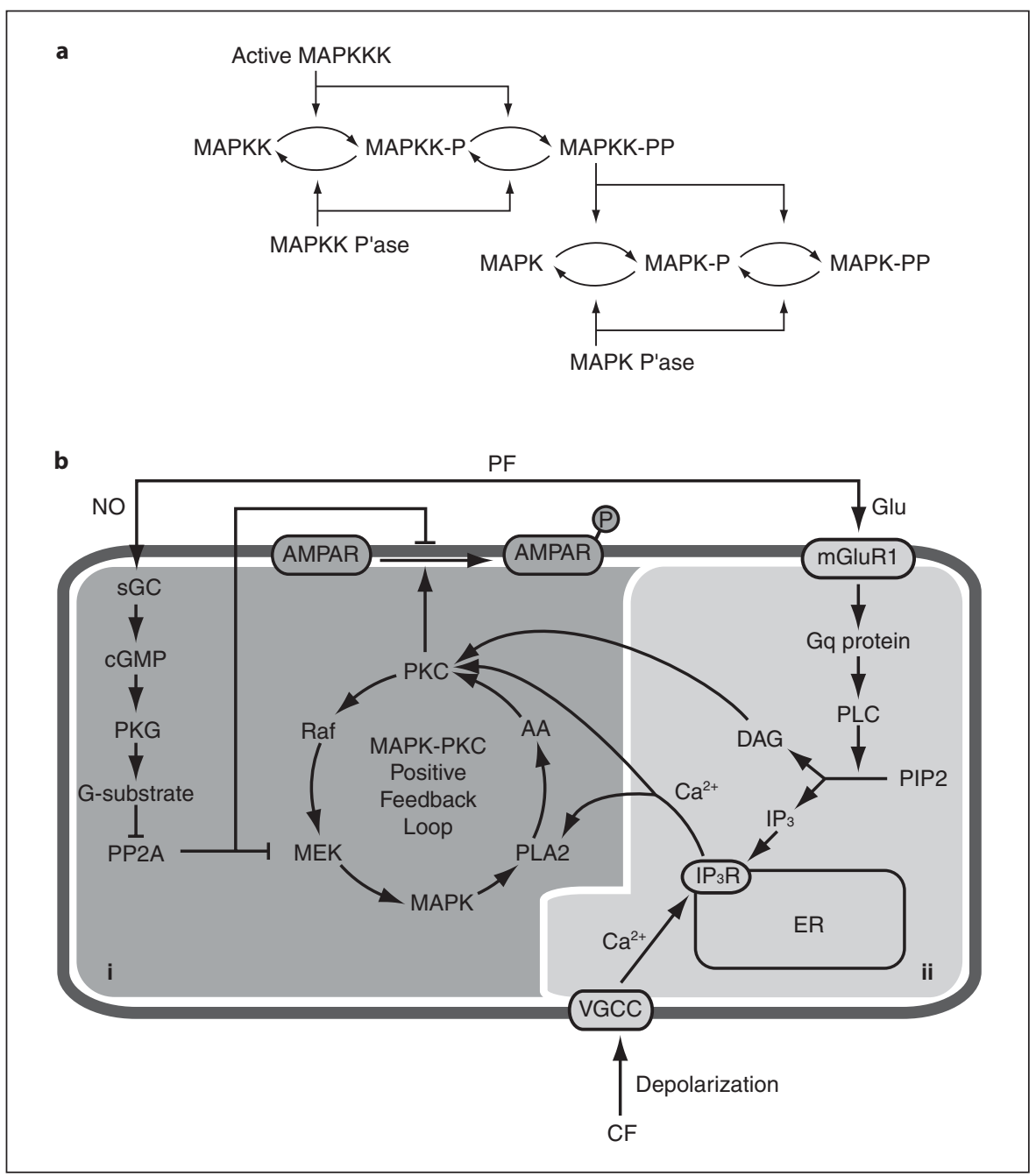

is termed 'ultrasensitivity' [57], and the most familiar examples are cooperative enzymes. In other cases, a cellular system has two stable steady states and jumps from one to the other, avoiding the intermediate states. This kind of switch is termed 'bistability' [54]. A bistable system displays different stimulus-response relationships, depending on whether the system began in the ON state or the OFF state (hysteresis). Bistability is particularly important in neurobiology, since it has been implicated in the storage of cellular information.

In the 1950s, autocatalytic enzymes were predicted to have multiple stable steady states [58]. Conceptual models were proposed in the 1980s describing a biological switch formed by a kinase that is activated by itself or another kinase and inactivated by a phosphatase; these models, however, were abstract and lacked a solid molecular background $[59,60]$. Progress in molecular bi- ology has revealed that the MAPK cascade is very important in information processing of neurons and other types of cells [reviewed in 56, 61-66]. The cascade consists of MAPKKK, MAPKK, and MAPK (fig. 1a); MAPKKK activates MAPKK by dual phosphorylation, and similarly, MAPKK activates MAPK by dual phosphorylation [65]. Biochemical experiments and realistic simulations have shown that these 'two-collision mechanisms' result in ultrasensitivity of the MAPK cascade [67]. In theory, ultrasensitivity arises also when two opposing enzymes (e.g., a kinase and a phosphatase) operate at near-saturation levels (zero-order ultrasensitivity) [57]. An ultrasensitive MAPK cascade response can be converted into a true all-or-none bistable response when there is a pathway that connects the output and input of the MAPK cascade and forms a positive feedback loop [68-70; but see also 71]. 


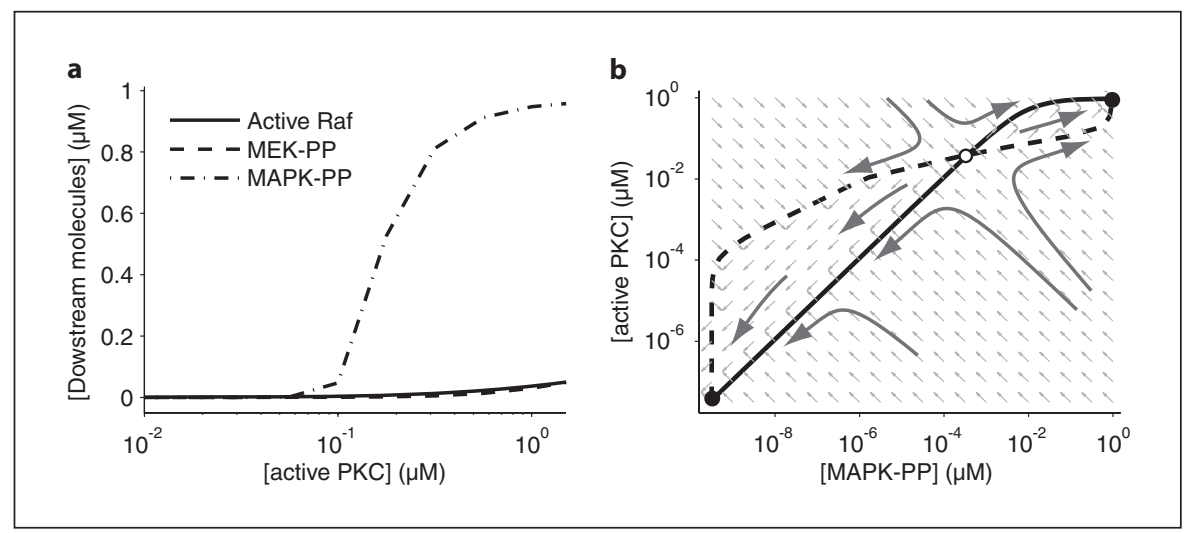

Fig. 2. Supralinearity and bistability of the MAPK-PKC positive feedback loop. a [Active Raf], [MEK-PP], and [MAPK-PP] plotted against various concentrations of active $\mathrm{PKC}$ that were kept constant throughout each simulation. [Active PP2A] was kept constant at $85 \mathrm{nM}$, and total concentrations of Raf, MEK, and MAPK were $0.5,0.5$ and $1 \mu \mathrm{M}$, respectively. $\mathbf{b}$ Phase plane analysis of the MAPK-PKC positive feedback loop. [Active PP2A] was kept constant at $85 \mathrm{nM}$. The solid bold line indicates the steady state [active $\mathrm{PKC}$ ] plotted against various concentrations of MAPK-PP that were kept constant throughout each simulation; likewise, the dashed bold line indicates the steady state [MAPK-PP] plotted against various [active PKC]. Filled circles and an open circle indicate stable steady states and an unstable steady state, respectively. Thin arrows indicate one of four directions, i.e., northeast, northwest, southwest, and southeast, which each point in the phase plane is directed towards. Schematic trajectories are superimposed (thick arrows).
Kuroda et al. [48] hypothesized that the MAPK cascade and other enzymes in the PC, e.g., PLA2 and PKC, make a positive feedback loop, which plays a pivotal role in LTD. The following is a description of the feedback loop and the peripheral pathways that they modeled (fig. 1b-i). Conjunctive PF-CF inputs result in increased $\left[\mathrm{Ca}^{2+}\right]$ and [diacylglycerol (DAG)] in PC dendritic spines. $\mathrm{Ca}^{2+}$ and DAG transiently activate conventional PKC (cPKC), a PKC isoform that is sensitive to both $\mathrm{Ca}^{2+}$ and DAG. cPKC also activates Raf, a MAPKKK, and Raf activates MEK, a MAPKK, through dual phosphorylation. Similarly, MEK activates MAPK through dual phosphorylation. Activated MAPK, as well as $\mathrm{Ca}^{2+}$, activates PLA2, resulting in the production of $A A$ and subsequent activation of cPKC. In this way, the MAPK cascade, PLA2, AA, and $\mathrm{cPKC}$ form a positive feedback loop (MAPK-PKC positive feedback loop). Activated cPKC phosphorylates AMPARs, and the phosphorylated receptors are eventually removed from the postsynaptic membrane through endocytosis. Thus, the magnitude of LTD corresponds to AMPAR phosphorylation. PF firing induces presynaptic synthesis of NO, which diffuses across the synaptic cleft and activates soluble guanylyl cyclase (sGC), which, in turn, catalyzes the conversion of guanosine triphosphate to cyclic guanylyl cyclase (cGMP). cGMP activates cGMPdependent protein kinase, which phosphorylates G-substrate. Phosphorylated G-substrate eventually inactivates protein phosphatase 2A (PP2A), an enzyme that dephosphorylates MEK and AMPARs. The Kuroda et al. model deals only with the initial and intermediate phases of cerebellar LTD, when cPKC is essential [72], but does not consider the late phase, which is CPKC-independent [72] and requires new protein synthesis $[4,7,21]$.

Simulations revealed that the initial phase of cerebellar LTD is dependent on direct activation of cPKC by $\mathrm{Ca}^{2+}$ and DAG, whereas the intermediate phase is mediated by activation of the MAPK-PKC positive feedback loop. The model also demonstrated an all-or-none property of AMPAR phosphorylation, within a time scale of approximately $40 \mathrm{~min}$. There was a sharp threshold level of input; stimuli greater than the threshold stereotypically resulted in AMPAR phosphorylation that was persistent for more than half an hour, whereas stimuli smaller than the threshold did not. This simulation result correlates with recent experiments and hypotheses that suggest that synapses alter their strength by jumping between discrete states, rather than shifting gradually [7375].

Previous studies $[68,69]$ have shown that the ultrasensitivity of the MAPK cascade is essential for the all-ornone property of the feedback loop the cascade constitutes, which the Kuroda et al. model is in accordance with. Figure 2a plots [active Raf], [doubly phosphorylated MEK (MEK-PP)], and [doubly phosphorylated MAPK 
(MAPK-PP)] against various concentrations of active PKC that were manipulated to remain constant throughout each simulation (data was produced for this review article; the model script can be found at http://www.cns. atr.jp/neuroinfo/kuroda/ and runs on simulation software, GENESIS/Kinetikit [76, 77]). The cascade output, [MAPK-PP] describes a sigmoidal curve with a large Hill coefficient of 4.5 (fig. 2a), indicating pathway ultrasensitivity. As mentioned earlier, the ultrasensitivity of the MAPK cascade is a result of the two-collision mechanisms of MEK and MAPK [67]. Zero-order ultrasensitivity [57] also seems to contribute because [active Raf] and [MEK-PP] are at ranges that are much lower than the concentrations of their substrates (fig. 2a).

AMPAR phosphorylation in the Kuroda et al. model is not permanent because the model takes into consideration the degradation of activated $\mathrm{CPKC}$ and recovery of PP2A from NO inactivation. To elucidate the dynamics of the MAPK-PKC positive feedback loop, these slow processes were eliminated from the model to guarantee the stability of the active state, and a phase plane analysis was performed for this review article (fig. 2b). Phase plane profiles are curves of one dependent variable against another and are used to determine whether a model has one or more steady states [78, also refer to 79 for another method that is useful for analyzing positive feedback systems consisting of more than two variables]. Nullclines in a phase plane indicate the values of a pair of variables, in which one of the variables is constant; the points of intersection are steady states. Two nullclines are shown in figure $2 \mathrm{~b}$; one is [active $\mathrm{cPKC}$ ] against [MAPK-PP] (solid bold line), and the other is [MAPK-PP] against [active cPKC] (dashed bold line). Schematic trajectories are superimposed (thick arrows). The figure indicates that the MAPK-PKC positive feedback loop is a bistable system, having two stable steady states (filled circle) and an unstable saddle point (open circle). It also demonstrates that the supralinear response of [MAPK-PP] against [active $\mathrm{PKC}]$ is critical for the bistability of the system because two curves would not intersect at more than two points if the response of MAPK-PP to active PKC followed a more gradual kinetics, such as Michaelis-Menten kinetics.

Tanaka et al. $[72,80]$ performed a series of slice experiments and verified the theoretical study. First, they demonstrated that MAPK acts downstream of PKC; a PKC inhibitor prevented MAPK activation and LTD that were induced by an LTD-induction protocol. Second, a MAPK inhibitor blocked the translocation of PKC, which is an indication of kinase activity. These findings indicate the existence of essential pathways through which MAPK and CPKC activate each other, supporting the hypothesis that MAPK and cPKC form a positive feedback loop that is pivotal for cerebellar LTD [48].

By locally photolysing caged calcium and using confocal imaging [81], Tanaka et al. subsequently demonstrated that elevation of $\left[\mathrm{Ca}^{2+}\right]$ alone is sufficient for the induction of cerebellar LTD, and they quantified the relationship between $\left[\mathrm{Ca}^{2+}\right]$ and LTD for the first time. LTD was induced stereotypically by $\left[\mathrm{Ca}^{2+}\right]$ elevations of substantial peak and duration, while small or short-term elevations in $\left[\mathrm{Ca}^{2+}\right]$ resulted in almost no LTD (fig. 3a). The sigmoidal relationship between peak $\left[\mathrm{Ca}^{2+}\right]$ and the amount of LTD (each curve in fig. 3a) was so supralinear that it could be described by the Hill equation with a large Hill coefficient of 5 (fig. 3a). Even though LTD was a supralinear function of $\left[\mathrm{Ca}^{2+}\right]$, the all-or-none property, which Kuroda et al. [48] had predicted, was not observed. It should be noted that Tanaka et al. measured average LTD of dozens of nearby synapses, not LTD of single synapses. The discrepancy between the experiments and simulations is reminiscent of previous experiments demonstrating that individual synaptic plasticity is discrete and heterogeneous, while these synapses present graded plasticity as a whole [75]. By modifying the Kuroda et al. model for a special form of LTD that was induced solely by $\mathrm{Ca}^{2+}$ and incorporating heterogeneity and noise into the model, the authors accurately simulated experimental measurements (fig. 3b) and confirmed the usefulness of the model in prediction and explanation of future experiments.

In order to verify that the MAPK-PKC positive feedback loop (fig. lb) is the underlying mechanism for supralinearity of LTD, they examined the relationship between $\left[\mathrm{Ca}^{2+}\right]$ and LTD subsequent to pharmacological prevention of AA production [80]. Treatment of cerebellar slices with a PLA2 inhibitor resulted in a stimulus-response curve that was much more gradual with a greatly reduced Hill coefficient (fig. 3c). This result was in agreement (qualitatively and quantitatively) with the corresponding simulation in which AA activation of cPKC was blocked (fig. 3d). The finding that positive feedback loop disruption results in the loss of supralinearity supports the hypothesis that the loop has a vital role in cerebellar LTD [48]. In addition, the results are in accordance with previous experiments and theoretical studies on the dynamics of positive feedback loops in biological contexts $[53,68,69]$.

Both the experiments and simulations revealed that the amount of required $\left[\mathrm{Ca}^{2+}\right]$ for LTD induction was a 
Fig. 3. Integration of $\left[\mathrm{Ca}^{2+}\right]$ during LTD. Results of experiments $(\mathbf{a}, \mathbf{c}, \mathbf{e}, \mathbf{g})$ and simulations $(\mathbf{b}, \mathbf{d}, \mathbf{f}, \mathbf{h})$ are shown side by side. a, b Relationship between peak $\left[\mathrm{Ca}^{2+}\right]$ and LTD for different durations of $\left[\mathrm{Ca}^{2+}\right]$ elevation. c, d Relationship between peak $\left[\mathrm{Ca}^{2+}\right]$ and LTD for different durations of $\left[\mathrm{Ca}^{2+}\right]$ elevation in the presence of a PLA2 inhibitor. e, f Relationship between integrated amount of $\left[\mathrm{Ca}^{2+}\right]$ and LTD. Data from the same experiments and simulations shown in panels $\mathbf{a}$ and $\mathbf{b}$, respectively. $\mathbf{g}, \mathbf{h}$ Data from panels $\mathbf{a}$ and $\mathbf{b}$ transformed by calculating $x$ from equation 2 . Smooth curves indicate fits of the Hill equation. Error bars in panels $\mathbf{a}, \mathbf{c}, \mathbf{e}$, and $\mathbf{g}$ indicate standard errors of measurement. This figure is reproduced from Tanaka et al. [80] with permission from Elsevier Inc.

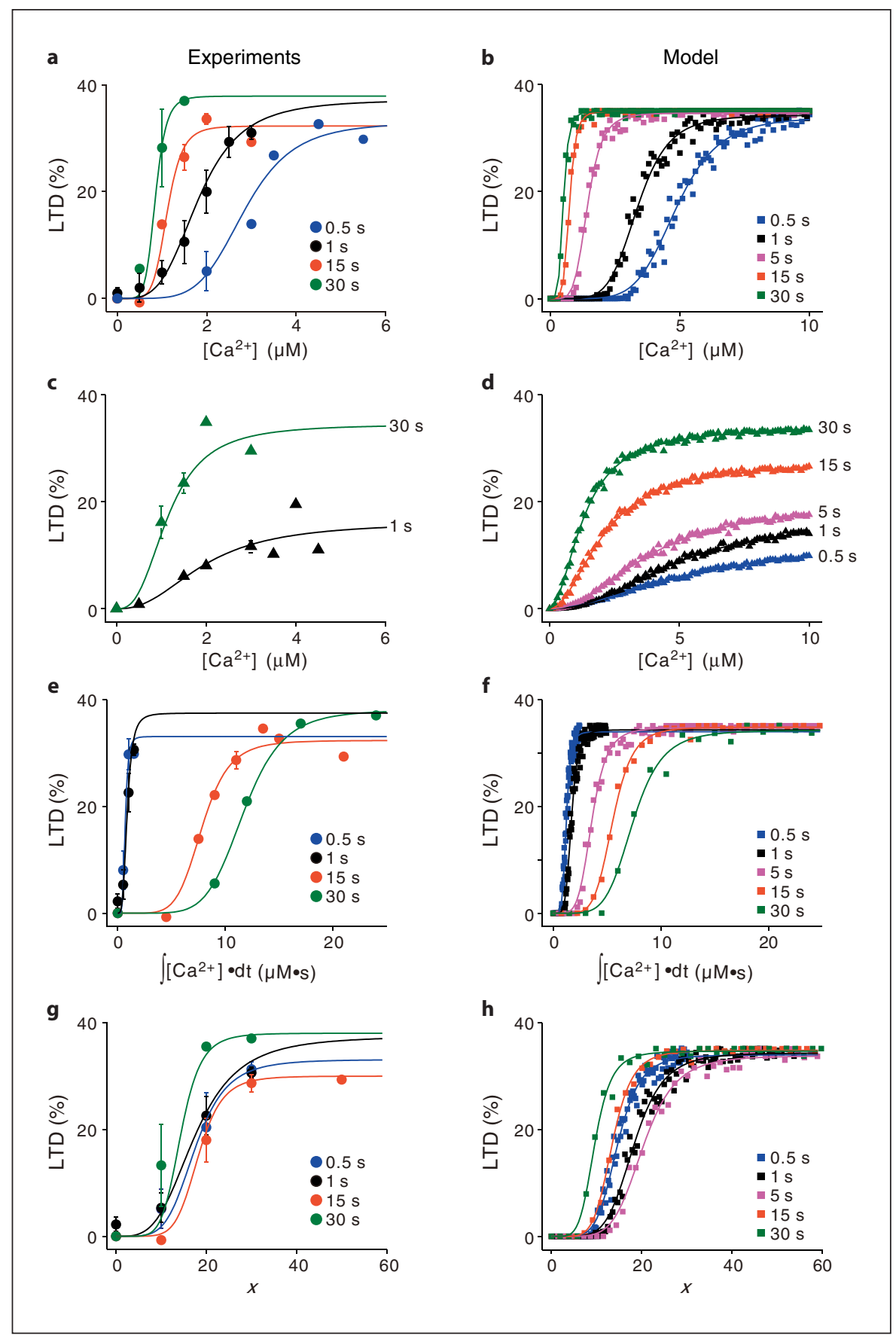

time-dependent variable. The longer the duration of a $\mathrm{Ca}^{2+}$ stimulus was, the lower the necessary $\left[\mathrm{Ca}^{2+}\right]$ peak was (fig. 3a, b), suggesting that the LTD induction mechanism integrates calcium signals over time. However, when the amount of LTD was plotted against the time integral of $\left[\mathrm{Ca}^{2+}\right]$, the integrated amount of required $\left[\mathrm{Ca}^{2+}\right]$ for LTD increased over time instead of being time- independent (fig. 3e, f), which suggests that the time integration process in LTD is somewhat leaky. Such a leaky integration of $\left[\mathrm{Ca}^{2+}\right]$ can be described mathematically as

$$
\tau \frac{d x}{d t}=-x+a\left[\mathrm{Ca}^{2+}\right](t)
$$


where $a$ is a scaling factor, $\tau$ is the time constant of the integration, and $x$ is the amount of downstream signal that transduces $\mathrm{Ca}^{2+}$ into LTD. In special cases where $\left[\mathrm{Ca}^{2+}\right]$ is elevated in a ramp-like fashion as in Tanaka et al. [80], the solution of equation 1 is

$$
x(t)=a k \tau \exp \left(-\frac{t}{\tau}\right)+a k(t-\tau)
$$

where $k$ is the rate of increasing $\left[\mathrm{Ca}^{2+}\right]\left(\right.$ peak $\left[\mathrm{Ca}^{2+}\right] \mathrm{di}-$ vided by the uncaging duration, $t$ ). After these parameters were paired to the experimental results ( $a$ and $\tau$ were $18.7 \% / \mu \mathrm{M}$ and $0.56 \mathrm{~s}$, respectively), the amount of LTD was plotted against $x$ in figure $3 \mathrm{~g}$ and $\mathrm{h}$. All the curves that were obtained at various durations of $\mathrm{Ca}^{2+}$ stimuli overlapped each other. The loss of time-dependence seen in figure $3 \mathrm{a}, \mathrm{b}, \mathrm{e}$, and $\mathrm{f}$ verifies equation 2 and supports the hypothesis that the signaling processes of LTD behave as a leaky integrator of $\left[\mathrm{Ca}^{2+}\right]$.

\section{Coincidence Detection of Cerebellar Inputs}

PF-PC plasticity is thought to be the cellular process of cerebellar supervised learning [10-12], but what molecular mechanisms enable the synapse to associate $\mathrm{PF}$ inputs (desired trajectories and sensory feedback) with CF inputs (error signals [3]) within a certain time window? Candidate coincidence detectors include (a) voltage-gated calcium channels (VGCCs) [23], (b) AMPARs [23], (c) PKC [23], (d) presynaptic membrane [82], and (e) $\mathrm{IP}_{3}$ Rs $[17,23,83]$. The scenarios for the candidates a-d are as follows: (a) simultaneous activation of PFs and the CF depolarizes the dendrite and induces $\mathrm{Ca}^{2+}$ influx through VGCCs in the spine, (b) glutamate released from PFs may sensitize AMPARs for phosphorylation, (c) protein tyrosine kinase activated by PF inputs, and $\left[\mathrm{Ca}^{2+}\right]$ elevated by $\mathrm{CF}$ inputs, cooperate to activate $\mathrm{PKC}$, (d) repetitive firing of PFs activates presynaptic NMDA-type glutamate receptors and induces NO synthesis. Upon simultaneous $\mathrm{CF}$ activity, a retrograde messenger, endocannabinoid might enhance $\mathrm{NO}$ release. Unfortunately, scenarios a-c cannot explain the $\sim 100$-ms PF-CF delay that is optimal for $\left[\mathrm{Ca}^{2+}\right]$ elevation and cerebellar LTD. Since there is no evidence that endocannabinoid enhances NO signaling, the presynaptic membrane (d) is not a likely candidate, either.

Then, is the $\mathrm{IP}_{3} \mathrm{R}(\mathrm{e})$ a probable coincidence detector? $\mathrm{IP}_{3} \mathrm{Rs}$ are located in a calcium store of the dendritic spine, the endoplasmic reticulum (ER). The receptor is synergistically activated by $\mathrm{Ca}^{2+}$ and $\mathrm{IP}_{3}$, and releases a large amount of $\mathrm{Ca}^{2+}$ from the ER in response, whereas excessive $\left[\mathrm{Ca}^{2+}\right]$ is inhibitory to the receptor $[84,85]$. Thus, the open probability of the $\mathrm{IP}_{3} \mathrm{R}$ is a bell-shaped function of $\left[\mathrm{Ca}^{2+}\right]$. On the one hand, PF firing activates PLC through the mGluR1 metabotropic glutamate receptor pathway, resulting in production of $\mathrm{IP}_{3}$ (and DAG) from phosphatidylinositol bisphosphate (fig. 1b-ii). On the other hand, CF firing depolarizes the PC and induces influx of $\mathrm{Ca}^{2+}$ through VGCCs. Therefore, $\left[\mathrm{IP}_{3}\right]$ and $\left[\mathrm{Ca}^{2+}\right]$ represent $\mathrm{PF}$ and $\mathrm{CF}$ activities, respectively, within the physiological range of inputs. By sensing sequential binding of $\mathrm{IP}_{3}$ and $\mathrm{Ca}^{2+}[17,23,83]$, the $\mathrm{IP}_{3} \mathrm{R}$ may act as a coincidence detector that associates PF inputs with CF inputs and releases a high amount of $\mathrm{Ca}^{2+}$ as its output signal, leading to LTD. However, massive stimulation of a PF bundle alone [86, $87]$, or uncaging either caged calcium or caged $\mathrm{IP}_{3}[16,88]$, can also induce LTD, which raises doubts that LTD is the cellular basis of cerebellar associative learning $[19,20]$.

To understand the spike-timing detection mechanism of cerebellar LTD, Doi et al. [49] developed a kinetic model of $\mathrm{Ca}^{2+}$ within a PC dendritic spine. As shown in figure $1 \mathrm{~b}$-ii, the model consists mainly of mGluR1s, Gq protein, PLC in the postsynaptic density (PSD), $\mathrm{IP}_{3} \mathrm{Rs}$ in the $\mathrm{ER}$, and VGCCs in the cytoplasmic membrane. The molecular pathway (as briefly mentioned in the previous paragraph) and parameter values were based on an extensive review of the biological literature. The simulations demonstrated that the supralinear $\mathrm{Ca}^{2+}$ response to conjunctive $\mathrm{PF}-\mathrm{CF}$ inputs is a regenerative process that is driven by the $\mathrm{IP}_{3} \mathrm{R}$. More specifically, $\left[\mathrm{Ca}^{2+}\right]$ elevation opens $\mathrm{IP}_{3} \mathrm{Rs}$, and outflow of $\mathrm{Ca}^{2+}$ from the ER results in additional $\left[\mathrm{Ca}^{2+}\right]$ elevation $\left(\mathrm{Ca}^{2+} \rightarrow \mathrm{IP}_{3} \mathrm{Rs} \rightarrow \mathrm{Ca}^{2+}\right)$, thereby producing a positive feedback loop. In theory, $\left[\mathrm{Ca}^{2+}\right]$ elevation may enhance the activity of $\mathrm{PLC}$ for $\mathrm{IP}_{3}$ production, and $\mathrm{IP}_{3}$ elevation may open $\mathrm{IP}_{3} \mathrm{Rs}$ to release $\mathrm{Ca}^{2+}$ from the ER, creating another positive feedback loop $\left(\mathrm{Ca}^{2+} \rightarrow \mathrm{PLC} \rightarrow \mathrm{IP}_{3} \rightarrow \mathrm{IP}_{3} \mathrm{Rs} \rightarrow \mathrm{Ca}^{2+}\right)$. However, simulations have demonstrated that this hypothetical pathway does not form a working positive feedback loop in the PC dendritic spine and denied the role of PLC in the supralinearity of $\mathrm{Ca}^{2+}$ influx. The $\mathrm{Ca}^{2+}$ response was largest when $\mathrm{CF}$ input followed PF input within an interval of 0-300 ms, which is consistent with experiments $[17,18]$ and the associative nature of cerebellar learning $[3-5,11]$. The time scale difference between a rapid electrical reaction $\left(\mathrm{Ca}^{2+}\right.$ influx by depolarization) and a slow biochemical reaction ( $\mathrm{IP}_{3}$ production by the metabotropic pathway) is critical for this spike-timing detection mechanism. Finally, there is a sharp threshold level of $\left[\mathrm{Ca}^{2+}\right]$ for $\mathrm{Ca}^{2+}$ induced $\mathrm{Ca}^{2+}$ release, and the threshold is regulated by 
$\left[\mathrm{IP}_{3}\right]$. In line with previous experiments [17], simulations demonstrated that a CF input within $300 \mathrm{~ms}$ after a PF input induced a $\mathrm{Ca}^{2+}$ transient, which easily reached the threshold of $\left[\mathrm{Ca}^{2+}\right]$ for regenerative $\mathrm{Ca}^{2+}$ release, because the threshold level was already lowered by the PF-mGluR1 pathway product, $\mathrm{IP}_{3}$. In contrast, when a $\mathrm{CF}$ input occurred either before or too late after PF inputs, the CFmediated elevation of $\left[\mathrm{Ca}^{2+}\right]$ failed to reach the threshold, because the threshold had already returned to a higher level as $\left[\mathrm{IP}_{3}\right]$ decreased. The $\mathrm{IP}_{3}$-dependent $\mathrm{Ca}^{2+}$ threshold is capable of explaining not only conjunctive LTD, but also LTD in non-physiological conditions. Even at the baseline $\left[\mathrm{IP}_{3}\right]$, where the $\mathrm{Ca}^{2+}$ threshold for regenerative $\mathrm{Ca}^{2+}$ release was highest, an excessive increase in $\left[\mathrm{Ca}^{2+}\right]$ could reach the threshold and induce LTD, as seen after massive activation of a PF bundle $[86,87]$ or $\mathrm{Ca}^{2+}$ uncaging [16]. Similarly, an extremely high $\left[\mathrm{IP}_{3}\right]$, typically seen upon $\mathrm{IP}_{3}$ uncaging [88], would result in LTD without requiring an increase in $\left[\mathrm{Ca}^{2+}\right]$ because the baseline $\left[\mathrm{Ca}^{2+}\right]$ is already greater than the $\mathrm{IP}_{3}$-regulated $\mathrm{Ca}^{2+}$ threshold. The descriptive power of the $\mathrm{Ca}^{2+}$ kinetics model indicates that the model captures the essence of the molecular mechanisms of cerebellar LTD.

Hernjak et al. [89] simulated the $\mathrm{Ca}^{2+}$ kinetics of PC dendrites and spines with realistic parameters, similarly to Doi et al. This study was unique in that they considered one- or two-dimensional diffusion and localization of molecules in addition to biochemical processes. They showed that high density and low sensitivity of the $\mathrm{IP}_{3} \mathrm{R}$ in the PC [90] are critical for generating and localizing $\mathrm{Ca}^{2+}$ spikes in a single dendritic spine. They also demonstrated that $\mathrm{Ca}^{2+}$ was compartmentalized in spines by their narrow neck, as predicted previously [91-93], whereas $\mathrm{IP}_{3}$ freely diffused into the dendrite and neighboring spines.

\section{The Role of NO in Context-Dependent Learning}

Recent studies have shown that a set of neurons that process a certain routine, such as use of scissors, are modularly organized in the cerebellum. Modules can be switched according to a given context of behavior [9496], so that animals can adapt to multiple environments. Little is known, however, about the biological mechanisms for context-dependent switching.

Ogasawara et al. [30] hypothesized that NO was crucial in context-dependent selection of learning modules because neighboring PF activity, which reflects the context of behavior, determines local [NO]. They combined established simulation models of electrophysiology, calcium dynamics (fig. $1 \mathrm{~b}$-ii), and intracellular signaling cascades (fig. 1b-i) [48, 49, 97], and further characterized the role of NO in cerebellar learning. The simulation results revealed that LTD was regulated by NO, whose concentration depended on surrounding PF activity. When $\mathrm{PF}$ activity in the vicinity was low, conjunctively stimulated PF-PC synapses were incapable of undergoing LTD, because of insufficient NO concentration. When PF activity was excessive, LTD spread to neighboring synapses where $[\mathrm{NO}]$ was high and $\left[\mathrm{Ca}^{2+}\right]$ was relatively low, and synaptic specificity was lost. LTD occurred in a synapsespecific manner only with moderate levels of nearby PF activity. Based on these results, the authors predicted that any movement made in any context was encoded by a small percentage of PFs because otherwise LTD would not occur at all or would be unspecific. Another hypothesis was that $\mathrm{NO}$ enables context-dependent selection of appropriate learning modules. An animal experiment was suggested to verify their hypotheses. For the detailed procedures, refer to the original paper [30].

\section{Stochasticity, Localization, Diffusion, and Scaffolding}

Mass-action kinetics is often a good approximation of biochemical reactions in relatively simple cells, such as Xenopus oocytes and undifferentiated culture cells [67, $68,98]$; however, it might not correctly describe the signaling pathways of the neuron for several reasons. First, the spine of an excitatory synapse, a key unit of neuronal information processing, is very small $(\sim 1 \mu \mathrm{m}$ or less in diameter) [99-101] and contains only a limited number of each molecular species. For instance, the number of AMPARs in a PF-PC synapse is as small as 4-73 [102]. In such cases, stochastic fluctuations come into play, and mass-action kinetics, described in continuous equations, is no longer applicable. Second, molecules are not mixed well in the spine. For instance, some receptors, enzymes, and scaffold proteins are elaborately arranged in the PSD to form a 'signaling machine' [103-105]. In particular, VGCCs, mGluRs, and PKC in the plasma membrane, and $\mathrm{IP}_{3} \mathrm{Rs}$ in the ER, are tied together by PSD proteins $[106$, 107], which suggests that the entire machinery for coincidence detection of PF-CF inputs [49] is organized into a single huge protein complex. Calcium ions form a nanodomain or microdomain around a calcium channel, affecting only adjacent calcium effectors and localizing their signals $[108,109]$, whereas diffusion of the effec- 
tors is important in information decoding of calcium spikes [110]. Finally, there are a variety of scaffolding proteins in the spine $[105,111,112]$, and they might affect important properties of signaling cascades, such as sensitivity, specificity, and supralinearity $[56,63,66,113-$ 115].

Some studies have addressed synaptic signaling and plasticity in conjunction with stochasticity, localization, and/or diffusion. CaMKII autophosphorylation is (controversially [116]) regarded as one of the candidates for long-term memory trace [117]. Its stability is likely to be limited by stochastic fluctuations, because there is an average of only 30 CaMKII holoenzymes per PSD [118]. Miller et al. [119] conducted Monte Carlo simulations [120] in order to elucidate factors that control switch stability, and to determine the functional relationship between stability and the number of molecules involved. The simulation demonstrated that the interplay between CaMKII and protein phosphatase I can form a bistable switch, whose stability depends exponentially on the number of enzyme molecules; the less the number of molecules, the more likely the switch is spontaneously turned on or off by stochastic fluctuations. The authors concluded that the number of CaMKII molecules found in the PSD ( 30 [118]) is sufficient for the switch to potentially retain information for life.

Santamaria et al. [121] combined optical experiments and computer simulations in order to characterize molecular diffusion along PC dendrites. By locally photolysing a caged diffusion marker, fluorescein dextran (FD), and using confocal imaging [81], they visualized diffusion of FD within dendrites and demonstrated that diffusion was remarkably slower in spiny dendrites than in smooth dendrites. In spiny dendrites, the mean-square displacement of FD molecules did not increase linearly with time, but instead increased hyperbolically; in other words, diffusion appeared to gradually slow down. It was in contrast with normal diffusion observed in smooth dendrites. This retardation, known as 'anomalous' diffusion [122], in spiny dendrites may play an important role in neuronal computation by affecting the spatial and temporal distribution of signaling molecules. To understand its mechanisms, the authors modeled the realistic three-dimensional (3D) structure of PC dendrites with or without spines. Simulations revealed that dendritic spines act as traps for molecules, slowing down the diffusion process. While Santamaria et al.'s model successfully explained why diffusion was anomalous in spiny dendrites, more abstract and lower-dimensional models of a dendrite [89] (mentioned in a previous section) underesti- mated the effects of spines on diffusion and failed to point at its anomalousness. This contrast may suggest the importance and advantage of realistic 3D simulation.

Neurotransmitters are released from the active zone of the presynaptic neuron, diffuse across the synaptic cleft, and bind to receptors at the opposing PSD. In some neurons, the transmitters are also released from sites outside the active zone and activate extrasynaptic receptors (ectopic release). To explore the significance of ectopic neurotransmission in the chick ciliary ganglion, Coggan et al. [123] simulated release of transmitter molecules as well as their diffusion and receptor binding by using a realistic 3D model. After exhaustive simulations, they concluded that most release was ectopic because otherwise the results would be inconsistent with experimental data.

Stochasticity, diffusion, and localization are very important factors in synaptic signaling and plasticity; however, the simulation of these factors is a huge computation load [124-126]. Nevertheless, Brownian motion of thousands of neurotransmitter molecules could be simulated exactly [123]. Other studies [127, 128] compromised between simulation speed and stochastic accuracy and utilized a method that dynamically chose between deterministic and stochastic calculations, depending on the number of molecules and propensity of forward reactions [129].

\section{Conceptual Models of Long-Term Memory}

The late phase of PF-PC LTD requires protein synthesis $[4,7,21]$, but once consolidated, cerebellar memory is no longer protein synthesis-dependent [130]. Consolidated memories might be transferred from the cerebellar cortices to the deep cerebellar nuclei, as suggested by some animal studies on adaptation of vestibulo-ocular and optokinetic reflexes [131, 132]. But what is the final form of memory traces in the cerebellum whether they reside in the cortices or the nuclei?

\section{Threshold Cascade Models}

Retention of information requires stability of synapses, and new learning requires plasticity. Neurons need to solve the dilemma between stability and plasticity [50], but the question is 'how?' Fusi et al. [133] suggested a conceptual cascade model, in which synapses are binary and have two levels of strength: weak and strong, both of 


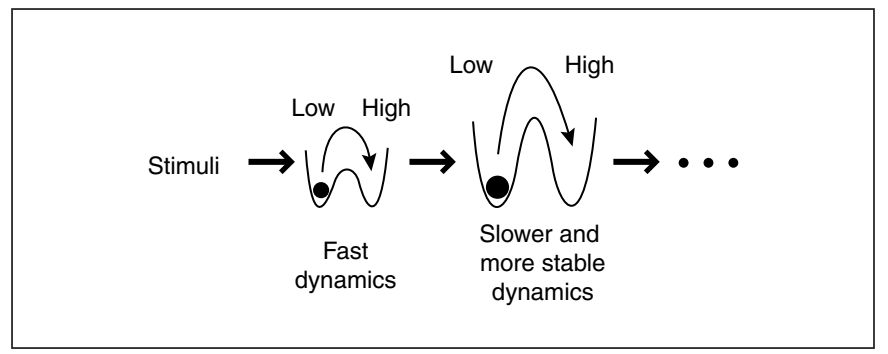

Fig. 4. Threshold cascade model. See text for explanation.

which are associated with their own cascade of multiple states. Whenever the conditions to reinforce the strength (i.e., applying an LTP induction protocol to a strong synapse and an LTD induction protocol to a weak synapse) are met, the state progresses further along the cascade, one step with each certain probability. Whenever the conditions to reverse synaptic strength (i.e., applying the LTD induction protocol to a strong synapse and the LTP induction protocol to a weak synapse) are met, the state jumps to the first step of the other cascade with another probability. The probability of transition depends on the depth of the current state within its cascade. The deeper the state is in the cascade, the more stable it is, and a transition is less likely to be made. The authors performed numerical simulations and demonstrated that (1) the plasticity and stability level that animals and humans possess is only possible with synapses whose states are linked by metaplastic transitions, and (2) the cascade model outperforms other similar models.

The Fusi et al. model provides an elegant theoretical solution for the stability versus plasticity dilemma; however, it unfortunately lacks a solid biological background. Taking into account the fact that bistability is ubiquitous in cellular systems [53, 54], Kawato [134] proposed a cascade of excitable and bistable dynamics (fig. 4). In his model, the fastest bistable system is activated by repetitive stimuli. The activated system then stimulates slower bistable dynamics that are more stable and require larger inputs for activation. In this way, activity is transmitted from one system to another slower one. Such a cascade of multiple bistable systems will form long-term memory that is stable, still open to modifications, and robust to noise.

This model is applicable to at least the first two steps of cerebellar LTD, i.e., $\mathrm{Ca}^{2+}$-induced $\mathrm{Ca}^{2+}$ release and the MAPK-PKC positive feedback loop (fig. 1b). $\mathrm{Ca}^{2+}$-induced $\mathrm{Ca}^{2+}$ release is a positive feedback loop, which is activated by conjunctive PF-CF stimuli, resulting in a supralinear $\mathrm{Ca}^{2+}$ release [49] (fig. $1 \mathrm{~b}$-ii). The ON state lasts only $1 \mathrm{~s}$, because $\mathrm{IP}_{3} \mathrm{Rs}$ are inactivated by a high concentration of $\mathrm{Ca}^{2+}$. The MAPK-PKC positive feedback loop is activated by repetitive inputs from the previous feedback loop, $\mathrm{Ca}^{2+}$-induced $\mathrm{Ca}^{2+}$ release, and remains in the ON state for about $1 \mathrm{~h}[48,72,80]$ (fig. $1 \mathrm{~b}-\mathrm{i}$ ).

\section{Bidirectional Long-Term Memory Model}

It is widely believed that memory is maintained in spine structures for extended periods in the brain [reviewed in 101, 112, 135-138], which might not be the case at least in the cerebellum and hippocampus. Sdrulla and Linden [139] demonstrated a surprising dissociation between LTD and spine morphology; chemically or synaptically evoked LTD in cerebellar slices was not associated with shrinkage or loss of dendritic spines. Manipulation that evoked significant spine retraction was not associated with LTD, either. A very similar 'double dissociation' between LTD and spine morphology was recently reported in the hippocampus [140]. In addition, spine structures can change very rapidly in a protein synthesis-independent manner [141], while, in contrast, long-term memory requires protein synthesis $[4,7,21]$. These findings suggest that long-term memory is retained by a mechanism other than spine morphology, and PKM $\zeta$ is probably the most likely candidate.

PKC isoforms are classified into three groups that differ in cofactor requirements: cPKCs, novel PKCs (nPKCs), and atypical PKCs (aPKCs). cPKCs require $\mathrm{Ca}^{2+}$ and DAG for activation; $\mathrm{nPKC}$ are $\mathrm{Ca}^{2+}$-independent and are activated by DAG alone; aPKCs are $\mathrm{Ca}^{2+}$ - and DAG-independent [reviewed in 142-144]. PKM $\zeta$ is a persistently active enzyme, consisting of the catalytic domain of an aPKC isoform, PKC $\zeta$. It is expressed in a brain-specific manner in various regions, including the hippocampus and cerebellar cortex $[145,146]$. A series of experiments performed mainly by Sacktor's group demonstrates accumulating evidence that $\mathrm{PKM} \zeta$ plays a pivotal role in longterm maintenance of memory. A procedure to induce hippocampal LTP first triggers transient activation of several PKC isoforms and translation of PKM $\zeta$; subsequently, $\mathrm{PKM} \zeta$ protein increases and replaces PKCs in 30 $\mathrm{min}$, and retains its activity for weeks [145, 147-150]. On the other hand, a procedure to induce hippocampal LTD reduces PKM $\zeta$ expression [151]. Injection of a PKM $\zeta$ inhibitor, ZIP [152], to the hippocampus reverses LTP maintenance in vivo and produces persistent loss of 1-day-old 


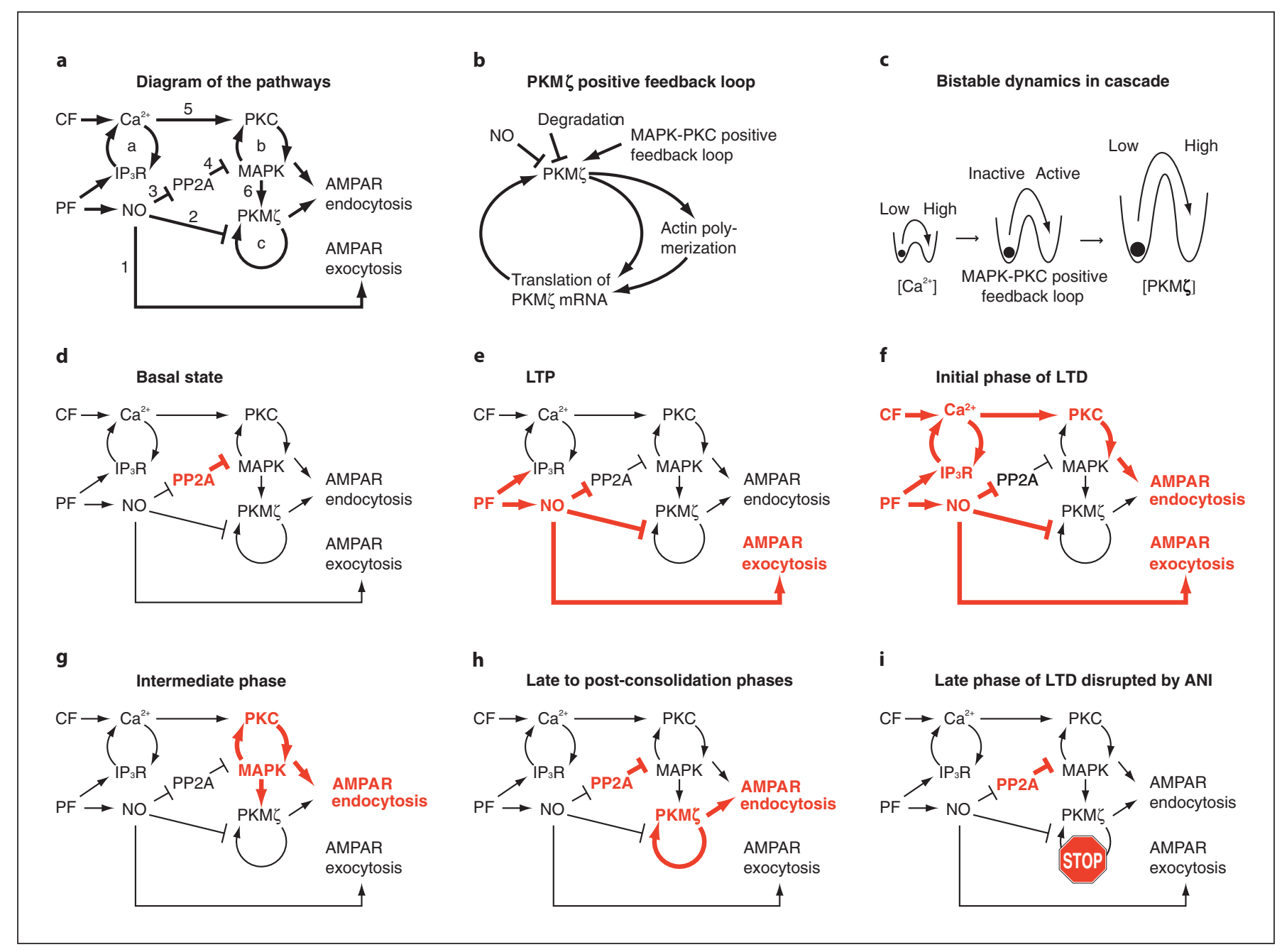

Fig. 5. Bidirectional long-term memory model. See text for explanation. a A schematic diagram of long-term memory. Sharp and blunt arrows indicate excitatory and inhibitory pathways, respectively. b The PKM $\zeta$ positive feedback loop. c The cascade model [134] representation of the bidirectional long-term memory model. $\mathbf{d}-\mathbf{i}$ Various states of memory (red bold lines and black thin lines indicate active and inactive pathways, respectively; red bold text and black thin text indicate active or increased molecules and inactive or decreased molecules, respectively): $\mathbf{d}$ the basal state, e LTP, $\mathbf{f}$ the initial, $\mathbf{g}$ intermediate, and $\mathbf{h}$ late to post-consolidation phases of LTD, and $\mathbf{i}$ the late phase of LTD disrupted by application of a protein synthesis inhibitor, such as anisomycin (ANI). spatial information [153]. More surprisingly, an injection of ZIP to the rat neocortex, which is regarded as the longterm repository of memory, erases associative memories as old as 1 month [154]. During hippocampal LTP, various kinases, such as CaMKII, MAPK, PKC, and preexisting $\mathrm{PKM} \zeta$, regulate new synthesis of PKM $\zeta$ [155]; PKM $\zeta$ is likely to be locally translated in synaptodendritic domains [156-161]. These findings strongly suggest that $\mathrm{PKM} \zeta$ is the (semi-)permanent form of a memory trace. Moreover, its importance to long-term memory is evolutionarily conserved from flies to rodents $[149,162]$. PKM $\zeta$ is also expressed in the cerebellar cortex [145, 146]. Since cerebellar plasticity is regarded as the mirror image of hippocampal plasticity, and shares much of its signaling cascade $[4,7,23,25,163], \mathrm{PKM} \zeta$ activity is likely to be central to cerebellar LTD, as it is to hippocampal LTP.

We propose a conceptual model that explains the stability and plasticity of cerebellar memory, postulating that PKM $\zeta$ activity is the persistent memory trace (fig. 5). The model will also provide insight into hippocampal plasticity, which has much in common with cerebellar plasticity; however, it should be noted that $\left[\mathrm{Ca}^{2+}\right]$ eleva- 
tion and protein kinase activity induce opposite effects in the cerebellum and hippocampus; high $\left[\mathrm{Ca}^{2+}\right]$ and active protein kinases result in LTD in the cerebellum and LTP in the hippocampus, while low $\left[\mathrm{Ca}^{2+}\right]$ and inactive kinases result in LTP in the cerebellum and LTD in the hippocampus [25].

\section{a. Pathways}

PF firing induces NO synthesis. NO transiently enhances exocytosis of GluR2 through S-nitrosylation of $\mathrm{N}$-ethylmaleimide-sensitive factor [164-167] (fig. 5a arrow 1). NO inactivates $\mathrm{PKM} \zeta$ at the same time (fig. $5 \mathrm{a}$ arrow 2). This pathway is hypothetical, but there is a good reason to assume its existence; LTD is reversed by [NO] elevation which little $\left[\mathrm{Ca}^{2+}\right]$ increase accompanies $[27,28$, 164]. Although NO enhances AMPAR exocytosis, that would not be enough for LTD reversal if the activity to maintain LTD, PKM $\zeta$ activity in this model, were not turned off at the same time. PKM $\zeta$ inactivation might be mediated through nitration of PKM $\zeta$ or its activator, phosphoinositide-dependent protein kinase-1 [155].

$\mathrm{NO}$ also inhibits PP2A in an sGC-dependent manner (fig. 5a arrow 3) and reverses PP2A inhibition (fig. 5a arrow 4), allowing for activation of the MAPK-PKC positive feedback loop $[4,23,168,169]$. Conjunctive firing of the $\mathrm{PF}$ and $\mathrm{CF}$ stimulates $\mathrm{IP}_{3} \mathrm{Rs}$, resulting in $\mathrm{Ca}^{2+}$-induced $\mathrm{Ca}^{2+}$ release (fig. 5a loop a). $\mathrm{Ca}^{2+}$ activates $\mathrm{cPKC}$ and PLA2 (fig. $1 \mathrm{~b}, 5 \mathrm{a}$ arrow 5), triggering activation of the MAPK-PKC positive feedback loop (fig. 5a loop b) [4, 23, $72,80,142,144]$. The active forms of MAPK and PKC induce expression of PKM $\zeta$ [155] (fig. 5a arrow 6).

We postulate a positive feedback loop that activates $\mathrm{PKM} \zeta$ translation in a $\mathrm{PKM} \zeta$-dependent manner (fig. 5a loop c, 5b) because PKM $\zeta$ activity is maintained for a surprisingly long period, much longer than the protein turnover timescale [147, 155]. The feedback loop consists of PKM $\zeta$, actin polymerization, and local synthesis of PKM $\zeta$, of which the latter two are PKM $\zeta$-dependent. Since a single effector, $\mathrm{PKM} \zeta$, acts on two steps, i.e., actin polymerization and translation of itself, this results in 'multistep ultrasensitivity' [57]. As Ferrell [53] mentioned, the combination of supralinearity and a positive feedback loop can produce bistability and all-or-none responses. This part of the model is based on the following experiments: (1) PKM $\zeta$ mRNA is present in spiny dendrites [161]; (2) expression of PKM $\zeta$ during hippocampal LTP induction is very rapid, and this kinase is likely to be synthesized locally on demand [145, 147, 148]; (3) PKC activation results in actin polymerization in the neuron [170], and $\mathrm{PKC} \zeta$ facilitates actin polymerization in various types of cells [171-174]; (4) F-actin levels linearly regulate protein synthesis capacity of living cells [175], and (5) PKC and MAPK induce expression of PKM $\zeta[147,148$, 161].

In the active state of the $\mathrm{PKM} \zeta$ positive feedback loop, endocytosis of AMPARs exceeds exocytosis, resulting in a depressed PF-PC synapse, whereas the inactive state of the feedback loop corresponds to a non-depressed synapse. As mentioned earlier, it should be noted that PKC activity (and presumably PKM activity as well) lead to the opposite effects in the cerebellum and hippocampus. In the PC, the Ser 880 phosphorylation of GluR2 subunits by PKC results in endocytosis of AMPARs and reduction of transmission efficacy $[4,176,177]$, while in the hippocampus, Ser818 phosphorylation of GluR1 subunits by PKC promotes synaptic incorporation of GluR1 and potentiation of synaptic transmission [178].

Central to the model are three positive feedback loops, i.e., $\mathrm{Ca}^{2+}$-induced $\mathrm{Ca}^{2+}$ release, the MAPK-PKC positive feedback loop, and $\mathrm{PKM} \zeta$-induced PKM $\zeta$ expression. Their decay time constants are $<1 \mathrm{~s}$, tens of minutes, and weeks or longer, respectively. Importantly, these bistable dynamics of different time scales are connected in a cascade. When stimuli activate the quickest dynamics (fig. 5a loop a) repetitively, activity is transmitted from the quickest, to the intermediate (fig. 5a loop b), and thereafter to the slowest and most stable dynamics (fig. 5a loop c). As a consequence, long-term stability and plasticity of memory is established. In this sense, this model is a more concrete representation of the cascade model of excitable dynamics (fig. 4, 5c) [134].

\section{b. Various States of Memory in the Model and \\ Corresponding Experiments}

In the basal state, PP2A is active and inhibits the MAPK-PKC positive feedback loop (fig. 5d).

\section{i. LTP Induction}

Postsynaptic LTP is induced in an NO-dependent manner by $\mathrm{PF}$ stimulation at $1 \mathrm{~Hz}$, which increases [NO], but $\left[\mathrm{Ca}^{2+}\right]$ only slightly $[27,33]$. When a calcium chelate was infused to the PC, LTD-inducing stimuli resulted in LTP instead [29]. More surprisingly, LTP was induced in cerebellar slices just by applying an NO donor alone [164]. The model corresponds well to these experimental findings (fig. 5e). In the model, NO, whose synthesis is triggered by PF spikes, transiently facilitates exocytosis of AMPARs. Meanwhile, NO liberates the MAPK-PKC positive feedback loop from PP2A inhibition, but the loop is not activated because of the lack of $\mathrm{Ca}^{2+}$ inputs. $\mathrm{PKM} \zeta$, 
if present, is inactivated by NO. As a consequence, the synapse is potentiated.

By the way, NO donors, such as nitroglycerin, are prescribed for the treatment of ischemic heart disease [179, 180]. However, these drugs do not usually cause ataxia or amnesia by disturbing synapses. This may appear to contradict our model, but it can be explained by the fact that systemic administration of an NO donor does not increase $[\mathrm{NO}]$ in neurons sufficiently to activate their intracellular signaling cascades, even at a dose that considerably affects hemodynamics [181].

\section{ii. Induction and Maintenance of LTD}

The model explains the sequence of events during LTD induction and maintenance (fig. $5 \mathrm{f}-\mathrm{h}$ ). When $\left[\mathrm{Ca}^{2+}\right]$ and $[\mathrm{NO}]$ are increased by conjunctive PF-CF activity, NO releases the MAPK-PKC positive feedback loop from PP2A inhibition, and $\mathrm{Ca}^{2+}$ activates $\mathrm{CPKC}$, which then phosphorylates and internalizes AMPARs (fig. 5f). In the intermediate phase (fig. 5g), the activated MAPK-PKC positive feedback loop maintains PKC activity and endocytosis. During, and subsequent to, the late phase (fig. 5h), newly synthesized PKM $\zeta$ maintains AMPAR phosphorylation and endocytosis for a long period of time. This time course corresponds to Tanaka et al.'s experimental findings [72]. They showed that cerebellar LTD was reduced or abolished by a cPKC inhibitor, bisindolylmaleimide I (BIM), when applied within $30 \mathrm{~min}$ of induction. In contrast, BIM application at a later time point did not affect the LTD time course, which suggests that CPKC is vital for LTD in the initial and intermediate phases, but not in the late phase. Late-phase LTD maintenance must be BIM-insensitive, and $\mathrm{PKM} \zeta$ is one of such PKC isoforms [182].

iii. Disruption of Late Phase LTD by Application of a Protein Synthesis Inhibitor

The model predicts that a protein synthesis inhibitor, such as anisomycin, disrupts late phase LTD by preventing expression of $\mathrm{PKM} \zeta$ (fig. 5i), whereas it does not affect the initial and intermediate phases. Once PKM $\zeta$ is sufficiently expressed (post-consolidation phase), only minimal synthesis of $\mathrm{PKM} \zeta$ is required in order to compensate for its degradation and maintain LTD. During this period, transient application of a protein synthesis inhibitor will fail to switch off the PKM $\zeta$ positive feedback loop, as long as the level of remaining PKM $\zeta$ is above the threshold for maintaining loop activity. These predictions correspond to in vitro and in vivo experiments. LTD induced in the presence of a protein synthesis in- hibitor is transient and vanishes within an hour [183]. In eyeblink conditioning, a protein synthesis inhibitor prevents ongoing consolidation of new memory, but does not affect consolidated memory [130].

\section{iv. Reactivation of Memory}

It has been demonstrated in the cerebellum [130], as well as in the hippocampus and amygdala [184-186], that consolidated memory of conditioning training becomes labile following its retrieval. In order for reactivated memory to be maintained, it must be reconsolidated through a protein synthesis-dependent pathway. The model can also explain this retrieval-induced deconsolidation of memory. Reactivation sessions, which are very similar to the training sessions, will result in increased $[\mathrm{NO}]$ and $\left[\mathrm{Ca}^{2+}\right]$ in the synapses that receive task-related inputs and store the conditioning memory (fig. 5f). NO inactivates the memory trace, $\mathrm{PKM} \zeta$, but at the same time the MAPK-PKC positive feedback loop is activated by $\mathrm{Ca}^{2+}$ and NO (fig. 5f, g). The typical steps of LTD induction are repeated, and this leads to new $\mathrm{PKM} \zeta$ synthesis (fig. $5 f \rightarrow g \rightarrow h$ ). As a result, the memory is maintained, despite NO inactivation of preexisting PKM $\zeta$. However, when a protein synthesis inhibitor is administered during retrieval sessions, the drug will block translation of PKM $\zeta$ (fig. 5i). Inactivation of preexisting $\mathrm{PKM} \zeta$ and inhibition of new PKM $\zeta$ synthesis will shut down the $\mathrm{PKM} \zeta$ loop activity and result in memory disruption. In contrast, co-administration of a protein synthesis inhibitor and a NOS inhibitor will not destroy memory, as predicted earlier [30]. It is because [NO] is kept at such a low level that existing PKM $\zeta$ will not be inactivated during the retrieval sessions.

\section{c. Experiments to Verify the Model}

First of all, it is necessary to determine whether PKM $\zeta$ maintains long-term memory in the cerebellum. If so, it should also be examined whether PKM $\zeta$ expression persists in the cerebellar cortex or shifts to the deep cerebellar nucleus, as experimentally suggested [187]. Second, according to the model, ZIP, a selective inhibitor of PKC $\zeta$ and PKM $\zeta$ [152], will abolish late phase LTD and associative memory, whereas overexpression of $\mathrm{PKM} \zeta$ will result in LTD. The model predicts that cerebellar postsynaptic LTP is protein synthesis-independent, in contrast to LTD $[4,21,23]$, since LTP corresponds to PKM $\zeta$ downregulation (fig. 5e). This could probably be tested in vivo as well as in vitro. In mice, cerebellar LTD and LTP have been shown to be cellular correlates of an increase and decrease in vestibulo-ocular reflex (VOR) gain, respective- 
ly [188]. If the model is correct, a protein synthesis inhibitor, as well as ZIP, will abolish the increase in VOR gain, without affecting its decrease.

\section{Future Perspectives}

Recent advances in experimental strategies and techniques, such as conditional transgenic and gene-targeting technologies and proteomic profiling [104, 189-193], have revealed a myriad of molecules that participate in memory formation. It is now thought that the majority of essential mediators of synaptic plasticity have been identified, so the next topic of interest will be to understand how these molecules can form memory elements in the microenvironment of the dendritic spine, where the ef- fects of stochastic noise, uneven localization, diffusion, and scaffolding are overwhelming. Efforts should also be made to untangle the intricate molecular interactions in the signaling networks $[47,55,193-202]$. To further our understanding of the fundamental mechanisms for synaptic plasticity, a combination of theoretical and experimental studies is very important.

\section{Acknowledgements}

We thank Prof. Erik De Schutter (Okinawa Institute of Science and Technology or OIST) for his valuable suggestions and advice, Mr. Stefan Wils (OIST) for fruitful discussion, and Ms. Miho Onizuka (Nara Institute of Science and Technology) for helpful comments on the manuscript. This work was supported by a grant from the Uehara Memorial Foundation.

\section{References}

1 Ito M: The Cerebellum and Neural Control. New York, Raven Press, 1984.

$\checkmark 2$ Thach WT: A role for the cerebellum in learning movement coordination. Neurobiol Learn Mem 1998;70:177-188.

3 Kawato M: Internal models for motor control and trajectory planning. Curr Opin Neurobiol 1999;9:718-727.

4 Ito M: Cerebellar long-term depression: characterization, signal transduction, and functional roles. Physiol Rev 2001;81:11431195.

5 Yamamoto K, Kobayashi Y, Takemura A, Kawano K, Kawato M: Cerebellar plasticity and the ocular following response. Ann NY Acad Sci 2002;978:439-454.

6 Glickstein M: Thinking about the cerebellum. Brain 2006;129:288-290.

7 Ito M: Cerebellar circuitry as a neuronal machine. Prog Neurobiol 2006;78:272-303.

$\checkmark 8$ Knudsen EI: Supervised learning in the brain. J Neurosci 1994;14:3985-3997.

$\checkmark 9$ Doya K: What are the computations of the cerebellum, the basal ganglia and the cerebral cortex? Neural Netw 1999;12:961-974.

10 Marr D: A theory of cerebellar cortex. J Physiol 1969;202:437-470.

11 Ito M: Neurophysiological aspects of the cerebellar motor control system. Int J Neurol 1970;7:162-176

12 Albus JS: A theory of cerebellar function. Math Biosci 1971;10:25-61.

13 Ito M, Sakurai M, Tongroach P: Climbing fibre induced depression of both mossy fibre responsiveness and glutamate sensitivity of cerebellar Purkinje cells. J Physiol 1982;324: 113-134.
Sakurai M: Calcium is an intracellular mediator of the climbing fiber in induction of cerebellar long-term depression. Proc Natl Acad Sci USA 1990;87:3383-3385.

15 Lev-Ram V, Makings LR, Keitz PF, Kao JP, Tsien RY: Long-term depression in cerebellar Purkinje neurons results from coincidence of nitric oxide and depolarizationinduced $\mathrm{Ca}^{2+}$ transients. Neuron 1995;15: 407-415.

16 Miyata M, Finch EA, Khiroug L, Hashimoto $\mathrm{K}$, Hayasaka S, Oda SI, Inouye M, Takagishi Y, Augustine GJ, Kano M: Local calcium release in dendritic spines required for longterm synaptic depression. Neuron 2000;28: 233-244.

17 Wang SS, Denk W, Häusser M: Coincidence detection in single dendritic spines mediated by calcium release. Nat Neurosci 2000;3: 1266-1273.

18 Safo P, Regehr WG: Timing dependence of the induction of cerebellar LTD. Neuropharmacology 2007;54:213-218.

19 De Schutter E: Cerebellar long-term depression might normalize excitation of Purkinje cells: a hypothesis. Trends Neurosci 1995;18: 291-295.

20 Llinás R, Lang EJ, Welsh JP: The cerebellum, LTD, and memory: alternative views. Learn Mem 1997;3:445-455.

21 Daniel H, Levenes C, Crepel F: Cellular mechanisms of cerebellar LTD. Trends Neurosci 1998;21:401-407.

22 Ito M: Mechanisms of motor learning in the cerebellum. Brain Res 2000;886:237-245.

23 Ito M: The molecular organization of cerebellar long-term depression. Nat Rev Neurosci 2002;3:896-902.
24 Hartell NA: Parallel fiber plasticity. Cerebellum 2002;1:3-18.

25 Jörntell H, Hansel C: Synaptic memories upside down: bidirectional plasticity at cerebellar parallel fiber-Purkinje cell synapses. Neuron 2006;52:227-238.

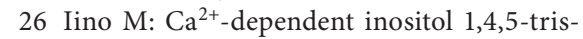
phosphate and nitric oxide signaling in cerebellar neurons. J Pharmacol Sci 2006;100: 538-544.

27 Lev-Ram V, Wong ST, Storm DR, Tsien RY: A new form of cerebellar long-term potentiation is postsynaptic and depends on nitric oxide but not cAMP. Proc Natl Acad Sci USA 2002;99:8389-8393.

28 Lev-Ram V, Mehta SB, Kleinfeld D, Tsien RY: Reversing cerebellar long-term depression. Proc Natl Acad Sci USA 2003;100:1598915993.

29 Coesmans M, Weber JT, De Zeeuw CI, Hansel C: Bidirectional parallel fiber plasticity in the cerebellum under climbing fiber control. Neuron 2004;44:691-700.

30 Ogasawara H, Doi T, Doya K, Kawato M: Nitric oxide regulates input specificity of longterm depression and context dependence of cerebellar learning. PLoS Comput Biol 2007; 3:e179.

31 Gally JA, Montague PR, Reeke GN Jr, Edelman GM: The NO hypothesis: possible effects of a short-lived, rapidly diffusible signal in the development and function of the nervous system. Proc Natl Acad Sci USA 1990; 87:3547-3551.

32 Lancaster JR Jr: Simulation of the diffusion and reaction of endogenously produced nitric oxide. Proc Natl Acad Sci USA 1994;91: 8137-8141. 
33 Shibuki K, Kimura S: Dynamic properties of nitric oxide release from parallel fibres in rat cerebellar slices. J Physiol 1997;498:443452.

>34 Wu J, Wang Y, Rowan MJ, Anwyl R: Evidence for involvement of the neuronal isoform of nitric oxide synthase during induction of long-term potentiation and long-term depression in the rat dentate gyrus in vitro. Neuroscience 1997;78:393-398.

>35 Casado M, Dieudonne S, Ascher P: Presynaptic $N$-methyl-D-aspartate receptors at the parallel fiber-Purkinje cell synapse. Proc Natl Acad Sci USA 2000;97:11593-11597.

\36 Qiu DL, Knöpfel T: An NMDA receptor/nitric oxide cascade in presynaptic parallel fiber-Purkinje neuron long-term potentiation. J Neurosci 2007;27:3408-3415.

-37 Susswein AJ, Katzoff A, Miller N, Hurwitz I: Nitric oxide and memory. Neuroscientist 2004; 10:153-162.

-38 Nagao S, Ito M: Subdural application of hemoglobin to the cerebellum blocks vestibuloocular reflex adaptation. Neuroreport 1991;2:193-196.

-39 Li J, Smith SS, McElligott JG: Cerebellar nitric oxide is necessary for vestibulo-ocular reflex adaptation, a sensorimotor model of learning. J Neurophysiol 1995;74:489-494.

-40 Yanagihara D, Kondo I: Nitric oxide plays a key role in adaptive control of locomotion in cat. Proc Natl Acad Sci USA 1996;93:1329213297.

-41 Hansel C, de Jeu M, Belmeguenai A, Houtman SH, Buitendijk GH, Andreev D, De Zeeuw CI, Elgersma Y: $\alpha$ CaMKII is essential for cerebellar LTD and motor learning. Neuron 2006;51:835-843.

42 Ahn S, Ginty DD, Linden DJ: A late phase of cerebellar long-term depression requires activation of CaMKIV and CREB. Neuron 1999;23:559-568.

$\checkmark 43$ Lee KH, Thompson RF: Multiple memory mechanisms in the cerebellum? Neuron 2006;51:680-682.

-44 Yuzaki M: The $\delta 2$ glutamate receptor: a key molecule controlling synaptic plasticity and structure in Purkinje cells. Cerebellum 2004; 3:89-93.

-45 Hirano T: Cerebellar regulation mechanisms learned from studies on GluR82. Mol Neurobiol 2006;33:1-16.

46 Safo PK, Regehr WG: Endocannabinoids control the induction of cerebellar LTD. Neuron 2005;48:647-659.

-47 Sanes JR, Lichtman JW: Can molecules explain long-term potentiation? Nat Neurosci 1999;2:597-604.

48 Kuroda S, Schweighofer N, Kawato M: Exploration of signal transduction pathways in cerebellar long-term depression by kinetic simulation. J Neurosci 2001;21:5693-5702.

-49 Doi T, Kuroda S, Michikawa T, Kawato M: Inositol 1,4,5-trisphosphate-dependent $\mathrm{Ca}^{2+}$ threshold dynamics detect spike timing in cerebellar Purkinje cells. J Neurosci 2005;25: 950-961.
50 Abraham WC, Robins A: Memory retention - the synaptic stability versus plasticity dilemma. Trends Neurosci 2005;28:73-78.

51 Ferrell JE Jr: Tripping the switch fantastic: how a protein kinase cascade can convert graded inputs into switch-like outputs. Trends Biochem Sci 1996;21:460-466.

52 Ferrell JE Jr: How regulated protein translocation can produce switch-like responses. Trends Biochem Sci 1998;23:461-465.

53 Ferrell JE Jr: Building a cellular switch: more lessons from a good egg. Bioessays 1999;21: 866-870.

54 Ferrell JE Jr: Self-perpetuating states in signal transduction: positive feedback, doublenegative feedback and bistability. Curr Opin Cell Biol 2002;14:140-148.

55 Tyson JJ, Chen KC, Novak B: Sniffers, buzzers, toggles and blinkers: dynamics of regulatory and signaling pathways in the cell. Curr Opin Cell Biol 2003;15:221-231.

56 Kolch W, Calder M, Gilbert D: When kinases meet mathematics: the systems biology of MAPK signalling. FEBS Lett 2005;579:18911895

57 Goldbeter A, Koshland DE Jr: An amplified sensitivity arising from covalent modification in biological systems. Proc Natl Acad Sci USA 1981;78:6840-6844.

58 Bierman A: Studies on the effects of struc ture on the behavior of enzyme systems. Bull Math Biophys 1954;16:203-257.

59 Lisman JE: A mechanism for memory storage insensitive to molecular turnover: a bistable autophosphorylating kinase. Proc Natl Acad Sci USA 1985;82:3055-3057.

60 Crick F: Memory and molecular turnover Nature 1984;312:101.

61 Impey S, Obrietan K, Storm DR: Making new connections: role of ERK/MAP kinase signaling in neuronal plasticity. Neuron 1999;23:11-14.

62 Peyssonnaux C, Eychene A: The Raf/MEK/ ERK pathway: new concepts of activation. Biol Cell 2001;93:53-62.

63 Sweatt JD: Mitogen-activated protein kinases in synaptic plasticity and memory. Curr Opin Neurobiol 2004;14:311-317.

64 Thomas GM, Huganir RL: MAPK cascade signalling and synaptic plasticity. Nat Rey Neurosci 2004;5:173-183.

65 Qi M, Elion EA: MAP kinase pathways. J Cell Sci 2005;118:3569-3572.

66 Kolch W: Coordinating ERK/MAPK signalling through scaffolds and inhibitors. Nat Rev Mol Cell Biol 2005;6:827-837.

67 Huang CY, Ferrell JE Jr: Ultrasensitivity in the mitogen-activated protein kinase cascade. Proc Natl Acad Sci USA 1996;93: 10078-10083.

68 Ferrell JE Jr, Machleder EM: The biochemical basis of an all-or-none cell fate switch in Xenopus oocytes. Science 1998;280:895898.

69 Bhalla US, Iyengar R: Emergent properties of networks of biological signaling pathways. Science 1999;283:381-387.
70 Bhalla US, Ram PT, Iyengar R: MAP kinase phosphatase as a locus of flexibility in a mitogen-activated protein kinase signaling network. Science 2002;297:1018-1023.

71 Markevich NI, Hoek JB, Kholodenko BN: Signaling switches and bistability arising from multisite phosphorylation in protein kinase cascades. J Cell Biol 2004;164:353359.

72 Tanaka K, Augustine GJ: A positive feedback protein kinase loop causes sustained PKC activation during cerebellar long-term depression. 36th Annual Meeting of the Society for Neuroscience, Atlanta 2006, pp 732.738/G737.

73 Petersen CC, Malenka RC, Nicoll RA, Hopfield JJ: All-or-none potentiation at CA3CA1 synapses. Proc Natl Acad Sci USA 1998; 95:4732-4737.

74 Montgomery JM, Madison DV: Discrete synaptic states define a major mechanism of synapse plasticity. Trends Neurosci 2004;27: 744-750.

75 O'Connor DH, Wittenberg GM, Wang SS: Graded bidirectional synaptic plasticity is composed of switch-like unitary events. Proc Natl Acad Sci USA 2005;102:96799684.

76 Bower JM, Beeman D: The Book of GENESIS: Exploring Realistic Neural Models with the GEneral NEural SImulation System, Internet ed. 2003

77 Vayttaden SJ, Bhalla US: Developing complex signaling models using GENESIS/Kinetikit. Sci STKE 2004;2004:pl4.

78 Ermentrout GB, Keizer JE: Qualitative analysis of differential equations; in Fall CP, Marland ES, Wagner JM, Tyson JJ (eds): Computational Cell Biology: An Introduction to Computer Modeling in Molecular Cell Biology. New York, Springer, 2002, pp 378-409.

79 Angeli D, Ferrell JE Jr, Sontag ED: Detection of multistability, bifurcations, and hysteresis in a large class of biological positive-feedback systems. Proc Natl Acad Sci USA 2004; 101:1822-1827.

$>80$ Tanaka K, Khiroug L, Santamaria F, Doi T, Ogasawara H, Ellis-Davies GC, Kawato M, Augustine GJ: $\mathrm{Ca}^{2+}$ requirements for cerebellar long-term synaptic depression: role for a postsynaptic leaky integrator. Neuron 2007;54:787-800

81 Wang SS, Augustine GJ: Confocal imaging and local photolysis of caged compounds: dual probes of synaptic function. Neuron 1995;15:755-760.

82 Duguid I, Sjöström PJ: Novel presynaptic mechanisms for coincidence detection in synaptic plasticity. Curr Opin Neurobiol 2006;16:312-322.

83 Berridge MJ: Neuronal calcium signaling. Neuron 1998;21:13-26

84 Iino $\mathrm{M}$ : Biphasic $\mathrm{Ca}^{2+}$ dependence of inositol 1,4,5-trisphosphate-induced Ca release in smooth muscle cells of the guinea pig taenia caeci. J Gen Physiol 1990;95:1103-1122. 
-85 Bezprozvanny I, Watras J, Ehrlich BE: Bellshaped calcium-response curves of Ins(1, 4,5)P3- and calcium-gated channels from endoplasmic reticulum of cerebellum. $\mathrm{Na}$ ture 1991;351:751-754.

86 Hartell NA: Strong activation of parallel fibers produces localized calcium transients and a form of LTD that spreads to distant synapses. Neuron 1996;16:601-610.

>87 Okubo Y, Kakizawa S, Hirose K, Iino M: Cross talk between metabotropic and ionotropic glutamate receptor-mediated signaling in parallel fiber-induced inositol 1,4,5trisphosphate production in cerebellar Purkinje cells. J Neurosci 2004;24:95139520.

88 Finch EA, Augustine GJ: Local calcium signalling by inositol-1,4,5-trisphosphate in Purkinje cell dendrites. Nature 1998;396: 753-756.

89 Hernjak N, Slepchenko BM, Fernald K, Fink CC, Fortin D, Moraru II, Watras J, Loew LM: Modeling and analysis of calcium signaling events leading to long-term depression in cerebellar Purkinje cells. Biophys J 2005;89: 3790-3806.

90 Fujiwara A, Hirose K, Yamazawa T, Iino M: Reduced $\mathrm{IP}_{3}$ sensitivity of $\mathrm{IP}_{3}$ receptor in Purkinje neurons. Neuroreport 2001;12: 2647-2651.

-91 Yuste R, Majewska A, Holthoff K: From form to function: calcium compartmentalization in dendritic spines. Nat Neurosci 2000;3: 653-659.

-92 Tsay D, Yuste R: On the electrical function of dendritic spines. Trends Neurosci 2004;27: 77-83.

$\checkmark 93$ Lee KJ, Kim H, Rhyu IJ: The roles of dendritic spine shapes in Purkinje cells. Cerebellum 2005;4:97-104.

-94 Imamizu H, Miyauchi S, Tamada T, Sasaki Y, Takino R, Putz B, Yoshioka T, Kawato M: Human cerebellar activity reflecting an acquired internal model of a new tool. Nature 2000;403:192-195.

-95 Imamizu H, Kuroda T, Miyauchi S, Yoshioka T, Kawato M: Modular organization of internal models of tools in the human cerebellum. Proc Natl Acad Sci USA 2003;100:54615466.

96 Imamizu H, Kuroda T, Yoshioka T, Kawato $\mathrm{M}$ : Functional magnetic resonance imaging examination of two modular architectures for switching multiple internal models. J Neurosci 2004;24:1173-1181.

$\checkmark 9$ De Schutter E, Bower JM: An active membrane model of the cerebellar Purkinje cell. I. Simulation of current clamps in slice. J Neurophysiol 1994;71:375-400.

-98 Sasagawa S, Ozaki Y, Fujita K, Kuroda S: Prediction and validation of the distinct dynamics of transient and sustained ERK activation. Nat Cell Biol 2005;7:365-373.

-99 Harris KM, Kater SB: Dendritic spines: cellular specializations imparting both stability and flexibility to synaptic function. Annu Rev Neurosci 1994;17:341-371.
100 Nimchinsky EA, Sabatini BL, Svoboda K: Structure and function of dendritic spines. Annu Rev Physiol 2002;64:313-353.

101 Carlisle HJ, Kennedy MB: Spine architecture and synaptic plasticity. Trends Neurosci 2005;28:182-187.

102 Masugi-Tokita M, Tarusawa E, Watanabe M, Molnar E, Fujimoto K, Shigemoto R: Number and density of AMPA receptors in individual synapses in the rat cerebellum as revealed by SDS-digested freeze-fracture replica labeling. J Neurosci 2007;27:21352144.

103 Kennedy MB: Signal-processing machines at the postsynaptic density. Science 2000; 290:750-754

104 Grant SG: The synapse proteome and phosphoproteome: a new paradigm for synapse biology. Biochem Soc Trans 2006;34:5963.

105 Boeckers TM: The postsynaptic density. Cell Tissue Res 2006;326:409-422.

106 Hwang JI, Kim HS, Lee JR, Kim E, Ryu SH, Suh PG: The interaction of phospholipase C- $\beta 3$ with Shank 2 regulates $m$ GluR-mediated calcium signal. J Biol Chem 2005;280: 12467-12473.

107 Mikoshiba K: Inositol 1,4,5-trisphosphate $\mathrm{IP}_{3}$ receptors and their role in neuronal cell function. J Neurochem 2006;97:16271633.

108 Franks KM, Sejnowski TJ: Complexity of calcium signaling in synaptic spines. Bioessays 2002;24:1130-1144.

109 Augustine GJ, Santamaria F, Tanaka K: Local calcium signaling in neurons. Neuron 2003;40:331-346.

110 Naoki H, Sakumura Y, Ishii S: Local signaling with molecular diffusion as a decoder of $\mathrm{Ca}^{2+}$ signals in synaptic plasticity. Mol Syst Biol 2005;1:2005.0027.

$\checkmark 11$ Cheng D, Hoogenraad CC, Rush J, Ramm E, Schlager MA, Duong DM, Xul P, Wijayawardana SR, Hanfelt J, Nakagawa T, Sheng M, Peng J: Relative and absolute quantification of postsynaptic density proteome isolated from rat forebrain and cerebellum. Mol Cell Proteomics 2006;5:1158-1170.

-112 Calabrese B, Wilson MS, Halpain S: Development and regulation of dendritic spine synapses. Physiology (Bethesda) 2006;21: 38-47.

113 Levchenko A, Bruck J, Sternberg PW: Scaffold proteins may biphasically affect the levels of mitogen-activated protein kinase signaling and reduce its threshold properties. Proc Natl Acad Sci USA 2000;97:58185823.

114 Harding A, Tian T, Westbury E, Frische E, Hancock JF: Subcellular localization determines MAP kinase signal output. Curr Biol 2005; 15:869-873.

115 Breitkreutz A, Tyers M: Cell signaling. A sophisticated scaffold wields a new trick. Science 2006;311:789-790.
116 Irvine EE, von Hertzen LS, Plattner F, Giese KP: $\alpha$ CaMKII autophosphorylation: a fast track to memory. Trends Neurosci 2006;29: 459-465.

117 Lisman J, Schulman H, Cline H: The molecular basis of CaMKII function in synaptic and behavioural memory. Nat Rev Neurosci 2002;3:175-190.

118 Petersen JD, Chen X, Vinade L, Dosemeci A, Lisman JE, Reese TS: Distribution of postsynaptic density (PSD)-95 and $\mathrm{Ca}^{2+} /$ calmodulin-dependent protein kinase II at the PSD. J Neurosci 2003;23:11270-11278.

119 Miller P, Zhabotinsky AM, Lisman JE, Wang XJ: The stability of a stochastic CaMKII switch: dependence on the number of enzyme molecules and protein turnover. PLoS Biol 2005;3:e107.

120 Gillespie DT: Exact stochastic simulation of coupled chemical reactions. J Phys Chem 1977;81:2340-2361.

121 Santamaria F, Wils S, De Schutter E, Augustine GJ: Anomalous diffusion in Purkinje cell dendrites caused by spines. Neuron 2006;52:635-648.

122 Klafter J, Sokolov IM: Anomalous diffusion spreads its wings. Phys World 2005;18:2932.

123 Coggan JS, Bartol TM, Esquenazi E, Stiles JR, Lamont S, Martone ME, Berg DK, Ellisman MH, Sejnowski TJ: Evidence for ectopic neurotransmission at a neuronal synapse. Science 2005;309:446-451.

124 Stiles J, Bartol T: Monte Carlo methods for simulating realistic synaptic microphysiology using MCell; in De Schutter E (ed): Computational Neuroscience: Realistic Modeling for Experimentalists. Boca Raton, CRC Press, 2001, pp 87-127.

125 Slepchenko BM, Schaff JC, Carson JH, Loew LM: Computational cell biology: spatiotemporal simulation of cellular events. Annu Rev Biophys Biomol Struct 2002;31: 423-441.

126 Turner TE, Schnell S, Burrage K: Stochastic approaches for modelling in vivo reactions. Comput Biol Chem 2004;28:165-178.

127 Bhalla US: Signaling in small subcellular volumes. I. Stochastic and diffusion effects on individual pathways. Biophys J 2004;87: 733-744.

128 Bhalla US: Signaling in small subcellular volumes. II. Stochastic and diffusion effects on synaptic network properties. Biophys J 2004;87:745-753.

129 Vasudeva K, Bhalla US: Adaptive stochastic-deterministic chemical kinetic simulations. Bioinformatics 2004;20:78-84.

130 Inda MC, Delgado-Garcia JM, Carrion AM: Acquisition, consolidation, reconsolidation, and extinction of eyelid conditioning responses require de novo protein synthesis. J Neurosci 2005;25:2070-2080.

$\checkmark 131$ Boyden ES, Katoh A, Raymond JL: Cerebellum-dependent learning: the role of multiple plasticity mechanisms. Annu Rev Neurosci 2004;27:581-609. 
132 Gittis AH, du Lac S: Intrinsic and synaptic plasticity in the vestibular system. Curr Opin Neurobiol 2006;16:385-390.

- 133 Fusi S, Drew PJ, Abbott LF: Cascade models of synaptically stored memories. Neuron 2005;45:599-611.

134 Kawato M: From 'understanding the brain by creating the brain' toward manipulative neuroscience. Philos Trans R Soc Lond B Biol Sci 2008 (in press).

135 Nikonenko I, Jourdain P, Alberi S, Toni N, Muller D: Activity-induced changes of spine morphology. Hippocampus 2002;12: 585-591.

-136 Kasai H, Matsuzaki M, Noguchi J, Yasumatsu N, Nakahara H: Structure-stabilityfunction relationships of dendritic spines. Trends Neurosci 2003;26:360-368.

137 Dudai Y: The neurobiology of consolidations, or, how stable is the engram? Annu Rev Psychol 2004;55:51-86.

138 Lynch G, Rex CS, Gall CM: LTP consolidation: substrates, explanatory power, and functional significance. Neuropharmacology 2007;52:12-23.

139 Sdrulla AD, Linden DJ: Double dissociation between long-term depression and dendritic spine morphology in cerebellar Purkinje cells. Nat Neurosci 2007;10:546-548.

140 Wang XB, Yang Y, Zhou Q: Independent expression of synaptic and morphological plasticity associated with long-term depression. J Neurosci 2007;27:12419-12429.

141 Lang C, Barco A, Zablow L, Kandel ER, Siegelbaum SA, Zakharenko SS: Transient expansion of synaptically connected dendritic spines upon induction of hippocampal long-term potentiation. Proc Natl Acad Sci USA 2004;101:16665-16670.

-142 Webb BL, Hirst SJ, Giembycz MA: Protein kinase C isoenzymes: a review of their structure, regulation and role in regulating airways smooth muscle tone and mitogenesis. Br J Pharmacol 2000;130:1433-1452.

143 Barry OP, Kazanietz MG: Protein kinase C isozymes, novel phorbol ester receptors and cancer chemotherapy. Curr Pharm Des 2001;7:1725-1744.

144 Metzger F, Kapfhammer JP: Protein kinase C: its role in activity-dependent Purkinje cell dendritic development and plasticity. Cerebellum 2003;2:206-214.

145 Hernandez AI, Blace N, Crary JF, Serrano PA, Leitges M, Libien JM, Weinstein G, Tcherapanov A, Sacktor TC: Protein kinase $\mathrm{M} \zeta$ synthesis from a brain mRNA encoding an independent protein kinase $\mathrm{C} \zeta$ catalytic domain. Implications for the molecular mechanism of memory. J Biol Chem 2003; 278:40305-40316

146 Oster H, Eichele G, Leitges M: Differential expression of atypical PKCs in the adult mouse brain. Brain Res Mol Brain Res 2004; 127:79-88.
147 Sacktor TC, Osten P, Valsamis H, Jiang X, Naik MU, Sublette E: Persistent activation of the $\zeta$ isoform of protein kinase $C$ in the maintenance of long-term potentiation. Proc Natl Acad Sci USA 1993;90:83428346.

148 Osten P, Valsamis L, Harris A, Sacktor TC: Protein synthesis-dependent formation of protein kinase $M \zeta$ in long-term potentiation. J Neurosci 1996;16:2444-2451.

149 Ling DS, Benardo LS, Serrano PA, Blace N, Kelly MT, Crary JF, Sacktor TC: Protein kinase $\mathrm{M} \zeta$ is necessary and sufficient for LTP maintenance. Nat Neurosci 2002;5:295296.

150 Serrano P, Yao Y, Sacktor TC: Persistent phosphorylation by protein kinase $\mathrm{M} \zeta$ maintains late-phase long-term potentiation. J Neurosci 2005;25:1979-1984.

151 Hrabetova S, Sacktor TC: Bidirectional regulation of protein kinase $\mathrm{M} \zeta$ in the maintenance of long-term potentiation and longterm depression. J Neurosci 1996;16: 5324-5333.

152 Puls A, Schmidt S, Grawe F, Stabel S: Interaction of protein kinase $\mathrm{C} \zeta$ with ZIP, a novel protein kinase C-binding protein. Proc Natl Acad Sci USA 1997;94:6191-6196.

153 Pastalkova E, Serrano P, Pinkhasova D, Wallace E, Fenton AA, Sacktor TC: Storage of spatial information by the maintenance mechanism of LTP. Science 2006;313:11411144.

154 Shema R, Sacktor TC, Dudai Y: Rapid erasure of long-term memory associations in the cortex by an inhibitor of $\mathrm{PKM} \zeta$. Science 2007;317:951-953.

155 Kelly MT, Crary JF, Sacktor TC: Regulation of protein kinase $\mathrm{M} \zeta$ synthesis by multiple kinases in long-term potentiation. J Neurosci 2007;27:3439-3444.

156 Klann E, Dever TE: Biochemical mechanisms for translational regulation in synaptic plasticity. Nat Rev Neurosci 2004;5:931942 .

157 Kelleher RJ 3rd, Govindarajan A, Tonegawa $S$ : Translational regulatory mechanisms in persistent forms of synaptic plasticity. Neuron 2004;44:59-73.

158 Sutton MA, Schuman EM: Dendritic protein synthesis, synaptic plasticity, and memory. Cell 2006;127:49-58.

159 Pfeiffer BE, Huber KM: Current advances in local protein synthesis and synaptic plasticity. J Neurosci 2006;26:7147-7150.

160 Martin KC, Zukin RS: RNA trafficking and local protein synthesis in dendrites: an overview. J Neurosci 2006;26:7131-7134.

161 Muslimov IA, Nimmrich V, Hernandez AI, Tcherepanov A, Sacktor TC, Tiedge H: Dendritic transport and localization of protein kinase $\mathrm{M} \zeta \mathrm{mRNA}$ : implications for molecular memory consolidation. J Biol Chem 2004;279:52613-52622.
162 Drier EA, Tello MK, Cowan M, Wu P, Blace N, Sacktor TC, Yin JC: Memory enhancement and formation by atypical PKM activity in Drosophila melanogaster. Nat Neurosci 2002;5:316-324.

163 Lynch MA: Long-term potentiation and memory. Physiol Rev 2004;84:87-136.

164 Kakegawa W, Yuzaki M: A mechanism underlying AMPA receptor trafficking during cerebellar long-term potentiation. Proc Natl Acad Sci USA 2005;102:17846-17851.

165 Huang Y, Man HY, Sekine-Aizawa Y, Han Y, Juluri K, Luo H, Cheah J, Lowenstein C, Huganir RL, Snyder SH: S-nitrosylation of $\mathrm{N}$-ethylmaleimide-sensitive factor mediates surface expression of AMPA receptors. Neuron 2005;46:533-540.

166 Hess DT, Matsumoto A, Kim SO, Marshall HE, Stamler JS: Protein S-nitrosylation: purview and parameters. Nat Rev Mol Cell Biol 2005;6:150-166.

167 Sossa KG, Beattie JB, Carroll RC: AMPAR exocytosis through NO modulation of PICK1. Neuropharmacology 2007;53:92-100.

168 Endo S, Nairn AC, Greengard P, Ito M: Thr123 of rat G-substrate contributes to its action as a protein phosphatase inhibitor. Neurosci Res 2003;45:79-89.

169 Launey T, Endo S, Sakai R, Harano J, Ito M: Protein phosphatase $2 \mathrm{~A}$ inhibition induces cerebellar long-term depression and declustering of synaptic AMPA receptor. Proc Natl Acad Sci USA 2004;101:676-681.

170 Pilpel Y, Segal M: Activation of PKC induces rapid morphological plasticity in dendrites of hippocampal neurons via Rac and Rho-dependent mechanisms. Eur J Neurosci 2004;19:3151-3164.

171 Gómez J, Martínez de Aragón A, Bonay P, Pitton C, García A, Silva A, Fresno M, Alvarez F, Rebollo A: Physical association and functional relationship between protein kinase $\mathrm{C} \zeta$ and the actin cytoskeleton. Eur J Immunol 1995;25:2673-2678.

172 Chodniewicz D, Zhelev DV: Chemoattractant receptor-stimulated F-actin polymerization in the human neutrophil is signaled by two distinct pathways. Blood 2003;101: 1181-1184.

173 Sun R, Gao P, Chen L, Ma D, Wang J, Oppenheim JJ, Zhang N: Protein kinase $\mathrm{C} \zeta$ is required for epidermal growth factor-induced chemotaxis of human breast cancer cells. Cancer Res 2005;65:1433-1441.

174 Wang HR, Zhang Y, Ozdamar B, Ogunjimi AA, Alexandrova E, Thomsen GH, Wrana JL: Regulation of cell polarity and protrusion formation by targeting RhoA for degradation. Science 2003;302:1775-1779.

175 Stapulionis R, Kolli S, Deutscher MP: Efficient mammalian protein synthesis requires an intact F-actin system. J Biol Chem 1997;272:24980-24986. 
-176 Chung HJ, Steinberg JP, Huganir RL, Linden DJ: Requirement of AMPA receptor GluR2 phosphorylation for cerebellar longterm depression. Science 2003;300:17511755.

- 177 Matsuda S, Launey T, Mikawa S, Hirai H: Disruption of AMPA receptor GluR2 clusters following long-term depression induction in cerebellar Purkinje neurons. EMBO J 2000;19:2765-2774.

178 Boehm J, Kang MG, Johnson RC, Esteban J, Huganir RL, Malinow R: Synaptic incorporation of AMPA receptors during LTP is controlled by a PKC phosphorylation site on GluR1. Neuron 2006;51:213-225.

179 Morrow DA, Gersh BJ, Braunwald E: Chronic coronary artery disease; in Zipes DP, Libby P, Bonow R, Braunwald E (eds): Braunwald's Heart Disease: A Textbook of Cardiovascular Medicine. Philadelphia, Saunders, 2004.

-180 Rosendorff C, Black HR, Cannon CP, Gersh BJ, Gore J, Izzo JL Jr, Kaplan NM, O’Connor CM, O'Gara PT, Oparil S: Treatment of hypertension in the prevention and management of ischemic heart disease: a scientific statement from the American Heart Association Council for High Blood Pressure Research and the Councils on Clinical Cardiology and Epidemiology and Prevention. Circulation 2007;115:2761-2788.

-181 Tassorelli C, Blandini F, Greco R, Nappi G: Nitroglycerin enhances cGMP expression in specific neuronal and cerebrovascular structures of the rat brain. J Chem Neuroanat 2004;27:23-32.
182 Messerschmidt A, Macieira S, Velarde M, Bädeker M, Benda C, Jestel A, Brandstetter $\mathrm{H}$, Neuefeind T, Blaesse M: Crystal structure of the catalytic domain of human atypical protein kinase $\mathrm{C}$ reveals interaction mode of phosphorylation site in turn motif. J Mol Biol 2005;352:918-931.

183 Linden DJ: A protein synthesis-dependent late phase of cerebellar long-term depression. Neuron 1996;17:483-490.

184 Nader K, Schafe GE, LeDoux JE: The labile nature of consolidation theory. Nat Rev Neurosci 2000;1:216-219.

185 Sara SJ: Retrieval and reconsolidation: toward a neurobiology of remembering Learn Mem 2000;7:73-84

186 Nader K: Memory traces unbound. Trends Neurosci 2003;26:65-72.

187 Shutoh F, Ohki M, Kitazawa H, Itohara S, Nagao S: Memory trace of motor learning shifts transsynaptically from cerebellar cortex to nuclei for consolidation. Neuroscience 2006;139:767-777.

188 Boyden ES, Katoh A, Pyle JL, Chatila TA, Tsien RW, Raymond JL: Selective engagement of plasticity mechanisms for motor memory storage. Neuron 2006;51:823834.

189 Bockamp E, Maringer M, Spangenberg C, Fees S, Fraser S, Eshkind L, Oesch F, Zabel B: Of mice and models: improved animal models for biomedical research. Physiol Genomics 2002;11:115-132.

190 Choudhary J, Grant SG: Proteomics in postgenomic neuroscience: the end of the beginning. Nat Neurosci 2004;7:440-445.

-191 Ptacek J, Snyder M: Charging it up: global analysis of protein phosphorylation. Trends Genet 2006;22:545-554.

192 Li KW: Proteomics of synapse. Anal Bioanal Chem 2007;387:25-28.
193 Linding R, Jensen LJ, Ostheimer GJ, van Vugt MA, Jorgensen C, Miron IM, Diella F, Colwill K, Taylor L, Elder K, Metalnikov P, Nguyen V, Pasculescu A, Jin J, Park JG, Samson LD, Woodgett JR, Russell RB, Bork P, Yaffe MB, Pawson T: Systematic discovery of in vivo phosphorylation networks. Cell 2007;129:1415-1426.

194 Tyson JJ, Chen K, Novak B: Network dynamics and cell physiology. Nat Rev Mol Cell Biol 2001;2:908-916.

195 Csete ME, Doyle JC: Reverse engineering of biological complexity. Science 2002;295: 1664-1669.

196 Milo R, Shen-Orr S, Itzkovitz S, Kashtan N, Chklovskii D, Alon U: Network motifs: simple building blocks of complex networks. Science 2002;298:824-827.

197 Barabasi AL, Oltvai ZN: Network biology: understanding the cell's functional organization. Nat Rev Genet 2004;5:101-113.

198 Papin JA, Hunter T, Palsson BO, Subramaniam S: Reconstruction of cellular signalling networks and analysis of their properties. Nat Rev Mol Cell Biol 2005;6:99-111.

199 Albert R: Scale-free networks in cell biology. J Cell Sci 2005;118:4947-4957.

200 Qi Y, Ge H: Modularity and dynamics of cellular networks. PLoS Comput Biol 2006; 2:e174.

201 Alon U: Network motifs: theory and experimental approaches. Nat Rev Genet 2007;8: 450-461.

202 Han Z, Vondriska TM, Yang L, Robb MacLellan W, Weiss JN, Qu Z: Signal transduction network motifs and biological memory. J Theor Biol 2007;246:755-761. 